\title{
The Spatial Distribution and Influencing Factors of Urban Cultural and Entertainment Facilities in Beijing
}

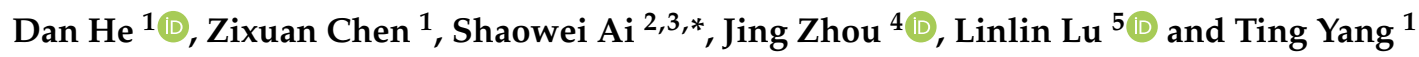 \\ 1 College of Applied Arts and Science, Beijing Union University, Beijing 100191, China; \\ hedan@buu.edu.cn (D.H.); $191070510101 @ b u u . e d u . c n$ (Z.C.); 20201070510112@buu.edu.cn (T.Y.) \\ 2 Key Research Institute of Yellow River Civilization and Sustainable Development, Henan University, \\ Kaifeng 475001, China \\ 3 Collaborative Innovation Center on Yellow River Civilization, Henan University, Kaifeng 475001, China \\ 4 Key Laboratory of Tibetan Environment Changes and Land Surface Processes, Institute of Tibetan Plateau \\ Research, Chinese Academy of Sciences, Beijing 100101, China; zhoujing@itpcas.ac.cn \\ 5 Key Laboratory of Digital Earth Science, Aerospace Information Research Institute, Chinese Academy of \\ Sciences, Beijing 100094, China; lull@radi.ac.cn \\ * Correspondence: aishaowei@henu.edu.cn; Tel./Fax: +86-371-2282-6115
}

Citation: He, D.; Chen, Z.; Ai, S. Zhou, J.; Lu, L.; Yang, T. The Spatial Distribution and Influencing Factors of Urban Cultural and Entertainment Facilities in Beijing. Sustainability 2021, 13, 12252. https://doi.org/ $10.3390 /$ su132112252

Academic Editor: George

D. Bathrellos

Received: 30 August 2021

Accepted: 2 November 2021

Published: 6 November 2021

Publisher's Note: MDPI stays neutral with regard to jurisdictional claims in published maps and institutional affiliations.

Copyright: (c) 2021 by the authors. Licensee MDPI, Basel, Switzerland. This article is an open access article distributed under the terms and conditions of the Creative Commons Attribution (CC BY) license (https:/ / creativecommons.org/licenses/by/ $4.0 /)$.

\begin{abstract}
Cultural and entertainment facilities are an important mainstay for urban development and the well-being of urban residents. Studying their spatial distribution is thus of great significance for improving urban functions and shaping urban characteristics. This paper uses the Simpson index, grid method, kernel density, nearest neighbor analysis and hierarchical clustering analysis to present in detail the spatial pattern, hotspot distribution and clustering characteristics of urban cultural and entertainment facilities in Beijing. With the help of the spatial lag model, the main factors affecting the spatial distribution of the facilities are explored. The results are as follows: Different types of cultural and entertainment facilities have different spatial agglomeration effects, which are closely related to the historical background of Beijing, industrial distribution, and the living needs of residents; the facilities generally present a spatial distribution with prominent centrality, strong clustering and significant heterogeneity; and financial insurance institution density, building density, securities company density, housing rent and distance to nearest scenic spot are the main factors affecting the distribution of the facilities. Analyzing the distribution characteristics and influencing factors of urban cultural and entertainment facilities in Beijing will provide typical cases and decision-making references that can underpin the informed layout and planning of urban cultural and entertainment industries and facilities.
\end{abstract}

Keywords: cultural and entertainment facilities; spatial clustering pattern; spatial heterogeneity; influencing factors; points of interest (POI)

\section{Introduction}

With the rapid development of the cultural and entertainment industry, the consumption of culture and entertainment has become an important part of residents' lives. The spatial distribution patterns of cultural and entertainment facilities have become important indicators to measure the quality of life of residents and the level of social and economic development [1,2]. Due to the increasing pressures of life and work, people urgently need cultural and entertainment activities to meet their spiritual and cultural enjoyment needs [3]. Global cultural and entertainment consumption exceeds USD 1 trillion, and among them, Americans spend USD 280 billion on culture and entertainment each year. The growth of production and wealth further liberates people's social needs and yearning for entertainment $[4,5]$. Cultural and entertainment consumption is not only restricted by the development of the social economy but also interacts with the social atmosphere [6,7]. Therefore, understanding the differentiation of the distribution of cultural and entertainment facilities is helpful to understand the regional characteristics of culture to a certain 
extent [8]. As an important function of the city and an important part of the urban spatial structure, the spatial distribution of cultural and entertainment facilities is not only related to the spatial structure of the city, but it even affects the recovery of urban functions [9]. At the same time, although the city's economy and built environment are gradually improving, the service delivery enjoyed by urban residents is very unevenly distributed [10,11]; this includes cultural and entertainment facilities. In the context of rapid economic development and spatial changes, there are huge differences in the supply of cultural services between different regions and between urban and rural areas, and there are also diversified groups within a city with different demands for cultural and entertainment services [12]. Therefore, understanding how to optimally arrange cultural and entertainment facilities is essential for enabling residents to enjoy a balanced cultural life [13]. This has become an important issue that geographers, urban planning scholars and government departments are increasingly concerned about.

The culture and entertainment industry has become a hot research field in academia since the mid to late 1990s [14]. The field of geography tends to focus on two major aspects: firstly, the spatial distribution characteristics of the cultural entertainment industry in cities and, secondly, its evolution and the influencing factors of spatial distribution (location distribution and site selection), with the ultimate aim of analyzing the cultural and entertainment industry at the local level [15-22]. The research scale is usually limited to a city or the main urban area of a city. The research conclusions provide reference values for the understanding of the spatial distribution characteristics of cultural and entertainment facilities in different areas of Beijing and the detailed planning of the urban cultural and entertainment industry.

Current research on urban cultural and entertainment facilities mainly focuses on the planning, design, adaptive transformation, spatial distribution and evolution characteristics and spatial influencing factors of urban cultural and entertainment facilities. First of all, in analyzing the spatial distribution and evolution characteristics of the cultural and entertainment industry, a variety of spatial analysis and visualization tools based on GIS (Geographic Information System) are widely used because it is a tool to visualize relevant conclusions. Huang et al. [23] found that Shanghai's (a city of China) cafes formed a spatial pattern of one main core and multiple secondary cores. The urban clustering effect is the most significant factor in the main urban area; different types of cafes have different spatial clustering characteristics. Jia et al. [24] found that Urumqi's (a city of China) cultural facilities are mostly distributed in science, education and cultural enrichment areas or multiethnic mixed living areas, which have become important hot spots for regional cultural exchanges. Yang et al. [25] found that the agglomeration characteristics of movie theaters in $X^{\prime}$ 'an (a city of China) changed significantly from 2011 to 2016, gradually expanding from the old city to the new suburban city and finally forming a new hotspot clustering area in the new city. Yu et al. [26] found that the Tongzhou District and Changping District of Beijing (a city of China) have formed multiple centers of cultural and entertainment facilities, which are areas with better cultural and entertainment development in the suburbs.

Secondly, in terms of analyzing the influencing factors of the spatial distribution of the cultural and entertainment industry, the urban social and cultural environment and residents' demands for cultural enjoyment have received more attention. Zhao et al. [27] found residents' cultural consumption habits, education levels and the cultural life atmosphere has an important impact on the distribution of different types of cultural facilities. In addition, the urban social space and the spatial evolution of culturally integrated commercial complexes have an impact on the distribution pattern of movie theaters [25]. Xue et al. [21] discovered that traditional cultural tourism areas and places rich in historical and cultural resources often have denser cultural and entertainment facilities. Some scholars construct models to incorporate multiple factors such as socioeconomics, transportation locations, cultural atmospheres, etc., to analyze in detail the spatial distribution of certain types of cultural and entertainment facilities. For example, Huang et al. [23] found that employed population density, road network density and the land price have a large influence on 
the number of the cafes, and chain cafes have higher requirements for traffic communication and consumer demand. The distance from the nearest colleges and universities has relatively larger influence on the number of independent cafes than other types of cafes. Therefore, the distribution of the independent cafes pays more attention to the innovation environment.

It is worth mentioning that Chinese scholars pay the most attention to the spatial distribution of cultural and entertainment facilities, while scholars from other countries pay more attention to urban green spaces, medical emergency facilities and other facilities that are closely related to people's health and safety [28-31]. In conclusion, research on cultural and entertainment facilities is relatively scarce. Throughout the research on the distribution of facilities, it is obvious that few scholars have conducted research on the spatial distribution of various types of cultural and entertainment facilities, especially in areas with developed cultural and entertainment industries such as Beijing. Furthermore, existing research is limited to the analysis of a single type of cultural and entertainment facilities, and there is still a lack of multi-index quantitative analysis of the impact of the social economy, the built environment and other factors on the spatial distribution of the overall cultural and entertainment facilities. Therefore, this study analyzed the distribution of cultural and entertainment facilities of Beijing, which is a developed area of innovation and development, that will help to comprehensively and deeply understand the current distribution of Beijing's cultural and entertainment industry and related issues and provide references for the planning and development of Beijing's cultural industry. Therefore, this study will address the following questions: What is the diversity pattern of cultural and entertainment facilities in the city area and in six urban districts? What are the spatial distribution characteristics of cultural and entertainment facilities in the city area and in six urban districts? What are the clustering characteristics of cultural and entertainment facilities in six urban districts? What are the scale effects and hierarchical characteristics of the clustering characteristics of cultural and entertainment facilities in six urban districts? How do factors such as social economy and the built environment affect the spatial distribution of cultural and entertainment facilities in six urban districts?

This research first used the Simpson Index to detect the diversity of the spatial distribution of cultural and entertainment facilities. Then, it analyzed the spatial distribution characteristics of different types of cultural and entertainment facilities. The grid method and kernel density method were used to analyze the spatial distribution of cultural and entertainment facilities. The nearest neighbor index was used to analyze the overall clustering characteristics of cultural and entertainment facilities in the six urban districts. The $\mathrm{K}$ function was used to analyze the clustering characteristics of cultural and entertainment facilities at different scales in the six urban districts. The nearest neighbor hierarchical cluster analysis was used to analyze the clustering hotspots of different levels of cultural and entertainment facilities in the six urban districts. Finally, a spatial regression model was constructed to analyze the influence of the social, economic and built environment on the spatial distribution of cultural and entertainment facilities and to identify the factors that significantly affect the distribution of cultural and entertainment facilities.

\section{Materials and Methods}

\subsection{Study Area}

Beijing is the capital of the People's Republic of China, a municipality directly under the Central Government, a national central city and a super-large city. China's political center, cultural center, international exchange center and scientific and technological innovation center have been approved by the State Council. As of 2020, the city has 16 districts with a total area of $16,410.54 \mathrm{~km}^{2}$ (Figure 1a). According to the seventh census data, as of 0:00 on 1 November 2020, the permanent population of Beijing is 21,893,095 [32]. Looking at Figure $1 b$, it is worth mentioning that there is no First Ring Road in Beijing. 


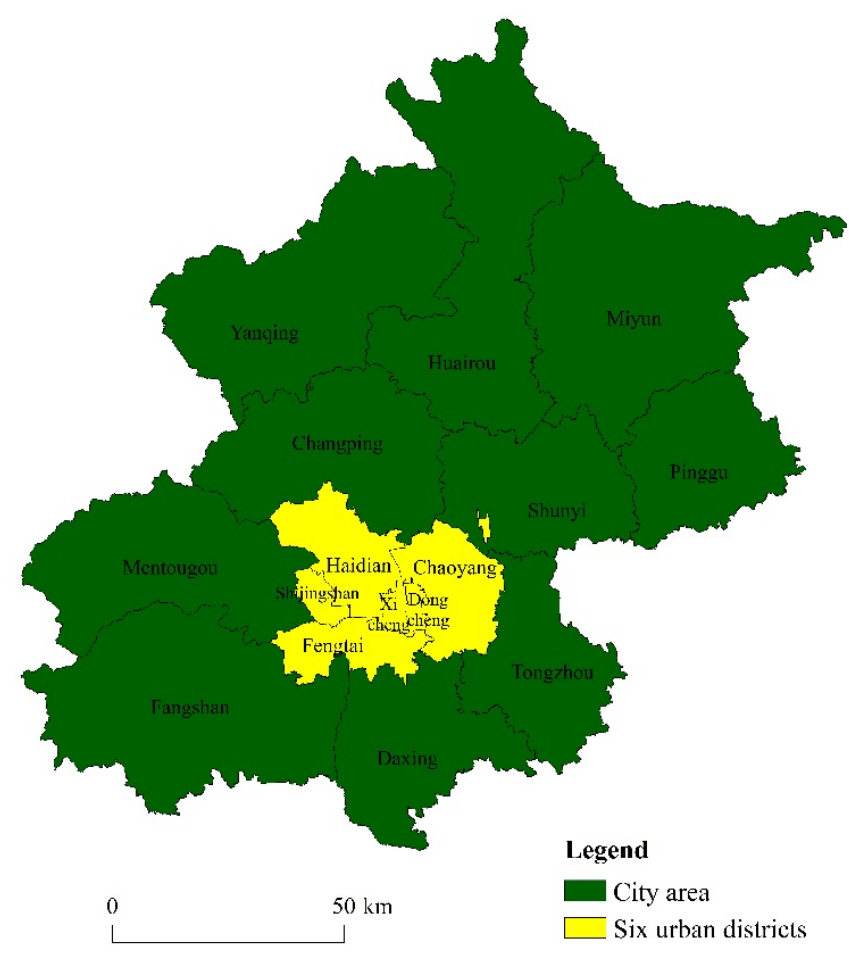

(a)

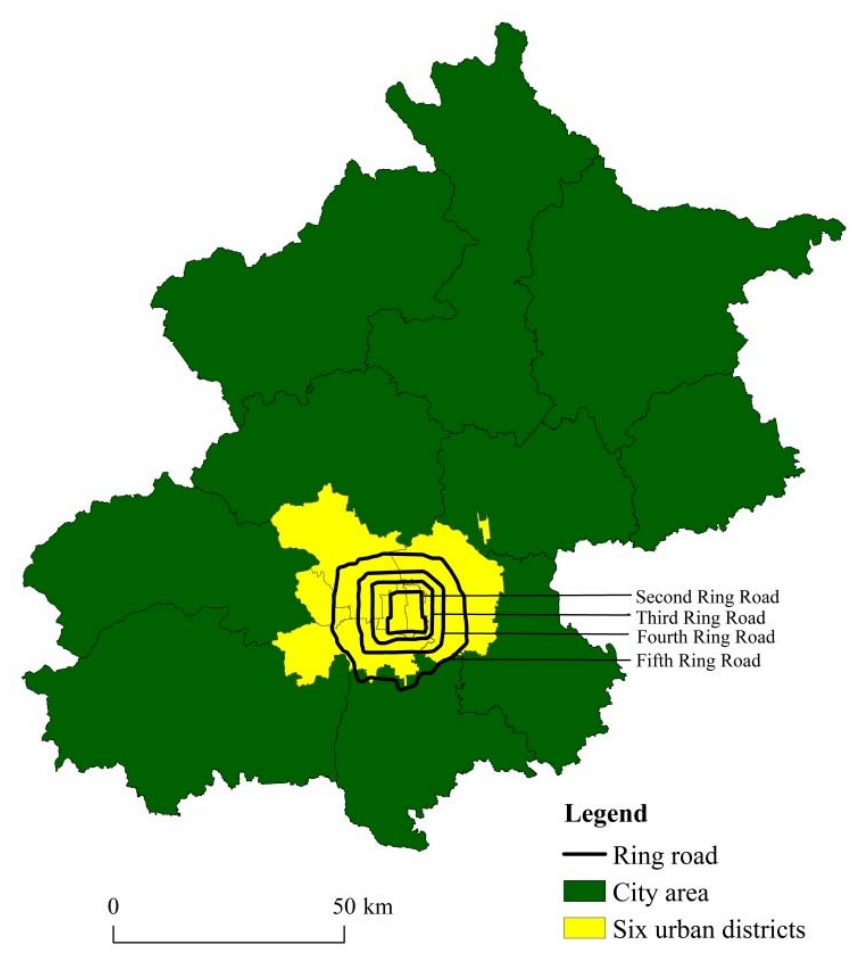

(b)

Figure 1. The administrative districts and ring roads map in Beijing. (a) The administrative districts; (b) The ring roads.

\subsection{Methods}

\subsubsection{Simpson Index}

The Simpson Index is commonly used to study the diversity of urban cultural and entertainment facilities. The Simpson Index is often used in the field of biology to judge community species diversity, which refers to the probability that two randomly sampled individuals belong to different species [33]. We use $1000 \mathrm{~m} \times 1000 \mathrm{~m}$ and $500 \mathrm{~m} \times 500 \mathrm{~m}$ grids for analysis in the city area and six urban districts, respectively, and obtain the result of the Simpson index of each grid. The Simpson Index is conducted on the Microsoft Excel 2010 platform.

\subsubsection{Grid Method}

To study the spatial distribution of cultural and entertainment facilities, we created grids of $1000 \mathrm{~m} \times 1000 \mathrm{~m}$ in the city area (the entirety of Beijing) and of $500 \mathrm{~m} \times 500 \mathrm{~m}$ in the six urban districts in Beijing and spatially connected the eight types of POI to the grid to obtain the number of POIs (Points of Interest) in a single grid. We established a grid system by creating fishing nets (ESRI ArcGIS 10.5 platform) and used the Spatial Join method (ESRI ArcGIS 10.5 platform) to count the number of POIs in each grid.

According to the Classification of Culture and Related Industries (2018) issued by the National Bureau of Statistics, the research of scholars such as Xue [21] and the actual distribution of facilities in Beijing, the cultural and entertainment industry is divided into eight categories: cinemas and theaters, clubs, bars, cafes, tea houses, internet cafes, leisure and fitness venues and parks and amusement parks. Data on cultural and entertainment facilities were obtained from the Baidu POI in 2018, and the total number is 15,198. The coordinates of the original POI are converted to the WGS84 coordinate system through the plugin (Baidu coordinate to earth coordinate tool, Shanghai Maice Data Technology Co., Ltd., Shanghai, China), and then the coordinates of POIs and the base map (GCS) are both the geodetic coordinate system. 


\subsubsection{Kernel Density Analysis}

Kernel density estimation is commonly used to estimate the spatial density distribution of geographical element [34,35], which is used to analyze the spatial hotspots of cultural and entertainment facilities in Beijing. This process is conducted at Spatial Analyst toolbox in ESRI ArcGIS for Desktop 10.5 platform.

\subsubsection{Analysis of the Spatial Clustering Characteristics of Points}

The nearest neighbor index method calculates the average distance between each element and its neighbors. If the index is less than the average distance of the assumed random distribution, the sample appears to be agglomerated globally; otherwise, it is scattered; if the index is equal to the average distance of the assumed random distribution, the sample is randomly distributed [36-38]. The nearest neighbor ratio is represented by $R$. Values $R=1, R<1$ and $R>1$ indicate random, agglomerated and scattered distributions of facilities, respectively, while $\mathrm{R}=2.1491$ indicates a uniform distribution [23]. The nearest neighbor index is conducted at ESRI ArcGIS 10.5 platform. The values of the nearest neighbor ratio are classified as very strong clustering $(0,0.25]$; strong clustering $(0.25,0.5]$; relatively strong clustering $(0.5,0.75]$; and ordinary clustering $(0.75,1)$.

The spatial distribution of the point ground objects will change with the spatial scale, and the Ripley's K function can analyze the spatial distribution of the point elements on any scale $[39,40]$. This tool can be used to analyze the characteristics of clustering or random distribution of elements within a certain distance range, and the spatial scale is the distance (Euclidean distance). Constructing the $\mathrm{L}$ function based on the $\mathrm{K}$ function is equivalent to the calculating the $\mathrm{K}$ function minus the desired value, making it easier to compare the difference with the completely random pattern. The Ripley's K function is conducted at CrimeStat 3.3 software (made by Ned Levine, Houston). The value of $\mathrm{L}$ function could reveal the spatial distribution of points, that is, when $\mathrm{L}=0$, the points have random distribution; when $\mathrm{L}>0$, the points have clustering distribution, and when $\mathrm{L}<0$, the points have uniform distribution.

The nearest neighbor hierarchical cluster analysis method can detect different degrees of clustering of point elements in space, so that the clustering areas can be identified in more detail. We specify at least the number of POIs included in each hotspot of the cluster level and then a limit distance or threshold of the clustering unit is defined correspondingly. When the distance of one point from other points is less than the limit distance, the point is classified as a clustering unit. Based on this, the original point is clustered into several regions, which are called first-order hot spots. By analogy, second-order and higher-order hot spots can be obtained [24]. The nearest neighbor hierarchical cluster analysis is finished at CrimeStat 3.3 software(made by Ned Levine, Houston, TX, USA).

\subsubsection{The Choice of Spatial Regression Model and the Variables}

In the last part of the study, influencing factors on the distribution of the cultural and entertainment facilities in six urban districts were studied through a spatial regression model. According to past studies [21,28,41], the POI density of cultural and entertainment facilities in the streets and towns is used as the dependent variable, while independent variables are the 13 selected indicators in the streets and towns (Table 1). It is worth mentioning that when analyzing the influencing factors of the spatial distribution of cultural and entertainment facilities in the six urban districts, the research scale has changed to the administrative division of streets and towns. The administrative division data were purchased from the website (http:/ / www.gscloud.cn/search accessed on 4 November 2019). In 2019, there were 331 streets and towns in Beijing. For the kind of density variables, the process is to use the "Spatial Join" method to associate the facilities to the corresponding street and town administrative division and then count the density of the facilities of each street and town. For the kind of distance variables, based on the road network data, we used the network analysis method to calculate the nearest network distance from each cultural and entertainment facility to the different index objects and then summed up all 
these nearest network distances and averaged them to obtain the average distance of all cultural and entertainment facilities in each street and town. For housing rent and land price, we use the spatial join method to associate each housing rent/land price point to the administrative division of each street and town and then calculate the average housing rent/land price of each street and town.

Table 1. Dependent and independent variables selection.

\begin{tabular}{|c|c|c|c|}
\hline Variable Name & Variable Code & Unit & Description \\
\hline POI density & POI_den & piece $/ \mathrm{m}^{2}$ & $\begin{array}{c}\text { The density of cultural and entertainment } \\
\text { facilities points }\end{array}$ \\
\hline Permanent resident population density & pop_den & $10^{4}$ people $/ \mathrm{m}^{2}$ & Permanent resident population density \\
\hline Distance to the nearest bus station & bus_sta & $\mathrm{m}$ & $\begin{array}{c}\text { Average distance from various facilities to the } \\
\text { nearest bus station }\end{array}$ \\
\hline Distance to the nearest metro station & subway_sta & $\mathrm{m}$ & $\begin{array}{c}\text { Average distance from various facilities to the } \\
\text { nearest metro station }\end{array}$ \\
\hline Road network density & luwang_den & $\mathrm{m} / \mathrm{m}^{2}$ & The density of main road and secondary road \\
\hline Distance to the nearest main road & zhugandao & $\mathrm{m}$ & $\begin{array}{c}\text { Average distance from various facilities to the } \\
\text { nearest major road }\end{array}$ \\
\hline Distance to the nearest secondary road & cigandao & $\mathrm{m}$ & $\begin{array}{c}\text { Average distance from various facilities to the } \\
\text { nearest secondary road }\end{array}$ \\
\hline Housing rent & housing rent & yuan $/ \mathrm{m}^{2}$ & Average of housing rents \\
\hline Distance to the nearest scenic spot & fengjingqu & $\mathrm{m}$ & $\begin{array}{l}\text { Average distance from various facilities to the } \\
\text { nearest scenic spots }\end{array}$ \\
\hline Distance to nearest institution of learning & gaoxiao & $\mathrm{m}$ & $\begin{array}{c}\text { Average distance from various facilities to } \\
\text { nearest high-level colleges }\end{array}$ \\
\hline Financial insurance institution density & jinrong_den & piece $/ \mathrm{m}^{2}$ & The density of financial insurance institution \\
\hline Securities company density & zhengquan_den & piece $/ \mathrm{m}^{2}$ & The density of securities company \\
\hline Building density & louyudasha_den & piece $/ \mathrm{m}^{2}$ & The density of building \\
\hline Land price & landprice & yuan $/ \mathrm{m}^{2}$ & Average of land prices \\
\hline
\end{tabular}

The origin data sources of independent variables are as follows. Among the 13 selected indicators in Table 1, the data of the resident population in the streets and towns come from the sixth census of China (2010); the housing rent point data come from https:// beijing.anjuke.com/?pi=PZ-baidu-pc-all-biaoti accessed on 3 July 2019; and Locomotive Collector (http: / / www.locoy.com/download accessed on 1 July 2019) was used to crawl all housing rent price data across Beijing in 3 July 2019. The total number of data in six urban districts is 13,145 ; the land price point data come from the official website of the Beijing Municipal Planning and Natural Resources Commission, and Houyi collector (https: / / www.houyicaiji.com/?type=download accessed on 1 July 2019) was also used to crawl all land price data across Beijing in 1 July 2019. In order to make the amount of data larger, it also includes the price of the land previously contracted in 2009-2018 from the same website, and we merged the data from 2009 to 2019. Types of land prices include business services, housing, industry, education and scientific research, finance, etc. After removing the non-coordinated land price points (data cleaning), the total number of this data in six urban districts is 3442; the remaining data (POI) were purchased from Gaode map in 2014.

Traditional ordinary least squares (OLS) regression does not consider the spatial relationship of the same variable in this area and that in adjacent areas, that is, it does not consider the issue of spatial autocorrelation. However, the spatial distribution of cultural and entertainment facilities is not only related to the socio-economic factors of this area, but also related to the spatial distribution of cultural and entertainment facilities in adjacent areas [21]. To determine if the spatial autocorrelation exists in the multi-linear regression, this study included the spatial weight matrix (first-order ROOK method) into the model and used OLS regression to test the results. The Lagrange Multiplier (LM) statistics are used to diagnose spatial autocorrelation of the results and to determine the spatial regression model according to its significance [24]. The first spatial regression model is the spatial lag 
model, which believes that the dependent variable $y$ is not only related to the independent variable $\mathrm{x}$ in this area but is also related to the dependent variable $\mathrm{y}$ in adjacent areas [42,43]. The second one is the spatial error model, which believes that the independent variable $\mathrm{x}$ is related to the dependent variable $y$ in this area, and it is also related to the independent variable $\mathrm{x}$ in adjacent areas [42]. The process of deciding whether to choose a spatial regression model and which spatial regression model to choose is as follows [44]. The first step is to perform OLS regression: if the results of LM (Lagrange Multiplier)-lag and LM (Lagrange Multiplier)-error are not significant, then the spatial regression is not necessary; if the results are significant, then the significant of the results of Robust LM-lag and Robust LM-error should be explored, and if the Robust LM-lag is significant, then the spatial lag model should be chosen. Otherwise, if the Robust LM-error is significant, the spatial error model should be chosen. If only one of the results of LM-lag and LM-error is significant, then the spatial lag model should be chosen only if the LM-lag is significant and the spatial error model should be chosen only if the LM-error is significant. The model selection and subsequent model operation are performed on GeoDa 1.6.7 software (developed by Luc Anselin).

We first used the min-max method to standardize the data and then check the multicollinearity among independent variables. When the eight factors including luwang_den, zhugandao, houseprice, fengjingqu, jinrong_den, zhengquan_den, louyudasha_den and landprice are retained, the multi-collinearity condition number is 16.161 , which is smaller than 30 , indicating that the multi-collinearity is not significant $[44,45]$. Next, we used OLS regression analysis to determine which spatial regression fits this research. Based on the calculated OLS regression results (Table 2), and according to the description in the previous paragraph, we finally chose the spatial lag model.

Table 2. The result of multiple linear regression (OLS method).

\begin{tabular}{cccc}
\hline Test & MI/DF & Value & Probability \\
\hline Moran's I (error) & 0.0074 & 0.6245 & 0.53228 \\
Lagrange Multiplier (lag) & 1 & 2.8575 & 0.09095 \\
Robust LM (lag) & 1 & 5.0428 & 0.02473 \\
Lagrange Multiplier (error) & 1 & 0.0191 & 0.88994 \\
Robust LM (error) & 1 & 2.2045 & 0.13761 \\
Lagrange Multiplier (SARMA) & 2 & 5.0620 & 0.07958 \\
\hline
\end{tabular}

In summary, the spatial lag model will be a tool used to analyze the factors affecting the spatial distribution of cultural and entertainment facilities. This model will provide the regression coefficient (characterizing positive and negative influences and strength of action), $p$-value (characterizing significance), standard deviation and z-value of each independent variable. The first two are used to analyze the influence of different factors on the distribution of cultural and entertainment facilities.

\section{Results}

\subsection{The Description of Cultural and Entertainment Facilities}

A total of 15,198 valid POIs are in the city area. The six urban districts contain 10,890 facilities in total, accounting for $71.65 \%$ of the total city area. Among them, the number of leisure and fitness venues is the largest, followed by cafes (Table 3). 
Table 3. The amount and structure of cultural and entertainment facilities in Beijing in 2018.

\begin{tabular}{ccccc}
\hline Facility Type & $\begin{array}{c}\text { The Number in Six } \\
\text { Urban Districts }\end{array}$ & $\begin{array}{c}\text { The Proportion of } \\
\text { Six Urban Districts }\end{array}$ & $\begin{array}{c}\text { The Number in the } \\
\text { City Area }\end{array}$ & $\begin{array}{c}\text { The Proportion of } \\
\text { City Area }\end{array}$ \\
\hline Cinemas and theaters & 296 & 2.72 & 360 & 2.37 \\
Clubs & 338 & 3.10 & 524 & 7.45 \\
Bars & 688 & 6.32 & 2479 & 16.31 \\
Cafes & 2150 & 19.74 & 1250 & 8.22 \\
Tea houses & 972 & 8.93 & 838 & 5.51 \\
Internet cafes & 517 & 4.75 & 7711 & 50.74 \\
Leisure and fitness venues & 5224 & 6.47 & 1252 & 8.24 \\
Parks and amusement parks & 705 & 100 & 15,198 & 100 \\
Total & 10,890 & & & \\
\hline
\end{tabular}

The POI distribution of the cultural entertainment facilities in various administrative districts is shown in Table 4. The number of the facilities in Chaoyang District (4336, accounting for 28.53 percent) is the highest, followed by Haidian (2683, accounting for 17.65 percent), Dongcheng (1296, accounting for 8.53 percent), Xicheng (1151, accounting for 7.57 percent), Fengtai (1084, accounting for 7.13 percent) and Changping (992, accounting for 6.53 percent).

Table 4. The amount and structure of cultural and entertainment facilities in each district in Beijing in 2018.

\begin{tabular}{|c|c|c|c|c|c|c|c|c|c|c|}
\hline $\begin{array}{l}\text { Administrative } \\
\text { District }\end{array}$ & $\begin{array}{l}\text { Cinemas } \\
\text { and } \\
\text { Theatres }\end{array}$ & Clubs & Bars & Cafes & $\begin{array}{c}\text { Tea } \\
\text { Houses }\end{array}$ & $\begin{array}{l}\text { Internet } \\
\text { Cafes }\end{array}$ & $\begin{array}{c}\text { Leisure } \\
\text { and Fitness } \\
\text { Venues }\end{array}$ & $\begin{array}{c}\text { Parks and } \\
\text { Amusement } \\
\text { Parks }\end{array}$ & $\begin{array}{l}\text { Total } \\
(/ \mathrm{Pc})\end{array}$ & $\begin{array}{l}\text { Proportion } \\
\quad(/ \%)\end{array}$ \\
\hline Dongcheng & 51 & 33 & 139 & 328 & 121 & 40 & 543 & 41 & 1296 & 8.53 \\
\hline Xicheng & 61 & 42 & 100 & 235 & 174 & 49 & 436 & 54 & 1151 & 7.57 \\
\hline Chaoyang & 97 & 129 & 329 & 982 & 276 & 165 & 2036 & 322 & 4336 & 28.53 \\
\hline Fengtai & 28 & 46 & 20 & 94 & 98 & 89 & 602 & 107 & 1084 & 7.13 \\
\hline Shijingshan & 8 & 13 & 5 & 24 & 30 & 28 & 190 & 42 & 340 & 2.24 \\
\hline Haidian & 51 & 75 & 95 & 487 & 273 & 146 & 1417 & 139 & 2683 & 17.65 \\
\hline $\begin{array}{l}\text { Six urban } \\
\text { districts total }\end{array}$ & 296 & 338 & 688 & 2150 & 972 & 517 & 5224 & 705 & 10,890 & 71.65 \\
\hline Fangshan & 7 & 17 & 11 & 18 & 29 & 27 & 217 & 66 & 392 & 2.58 \\
\hline Tongzhou & 12 & 17 & 10 & 59 & 45 & 72 & 405 & 66 & 686 & 4.51 \\
\hline Shunyi & 3 & 22 & 19 & 48 & 30 & 26 & 302 & 47 & 497 & 3.27 \\
\hline Changping & 11 & 37 & 27 & 82 & 53 & 70 & 643 & 69 & 992 & 6.53 \\
\hline Daxing & 11 & 24 & 8 & 55 & 41 & 72 & 345 & 87 & 643 & 4.23 \\
\hline Mentougou & 6 & 16 & 2 & 2 & 8 & 6 & 53 & 27 & 120 & 0.79 \\
\hline Huairou & 3 & 15 & 9 & 23 & 25 & 12 & 217 & 50 & 354 & 2.33 \\
\hline Pinggu & 2 & 22 & 1 & 10 & 17 & 13 & 80 & 39 & 184 & 1.21 \\
\hline Miyun & 5 & 12 & 7 & 19 & 20 & 9 & 144 & 60 & 276 & 1.82 \\
\hline Yanqing & 4 & 4 & 2 & 13 & 10 & 14 & 81 & 36 & 164 & 1.08 \\
\hline $\begin{array}{l}\text { City area } \\
\text { total }\end{array}$ & 360 & 524 & 784 & 2479 & 1250 & 838 & 7711 & 1252 & 15,198 & 100 \\
\hline
\end{tabular}

\subsection{Spatial Pattern of Cultural and Entertainment Facilities}

\subsubsection{Cultural and Entertainment Diversity Pattern}

Figure 2a shows that the overall cultural and entertainment diversity was greatest in the urban area and decreased from the center to the surroundings as the distance from the urban area increased. The areas with higher diversity in the outer suburbs (In Beijing, except for the six urban districts, all others belong to the suburbs) are the seat of the district government, such as in Daxing, Pinggu and Shunyi (please see Figure 1). It is worth mentioning that in suburban non-governmental locations, there are also areas with a high diversity of cultural and entertainment facilities, such as Huilongguan-Tiantongyuan, Capital Airport and Xihongmen, forming secondary centers of cultural and entertainment facility diversity. Figure $2 b$ shows that the diversity is relatively high within the Fourth 
Ring Road. At present, it seems that the cultural and entertainment diversity of the subcenter of Beijing is relatively high. However, the cultural and entertainment diversity of the outside of South Fourth Ring Road is relatively low, and the process of cultural construction is slow, which highlights the contrasting cultural and entertainment diversity between the northern and southern parts of Beijing. It is worth mentioning that the color settings for different levels are based on the natural break point classification method, which can appropriately group similar values to maximize the difference between different categories. Other similar figures all adopt this method.

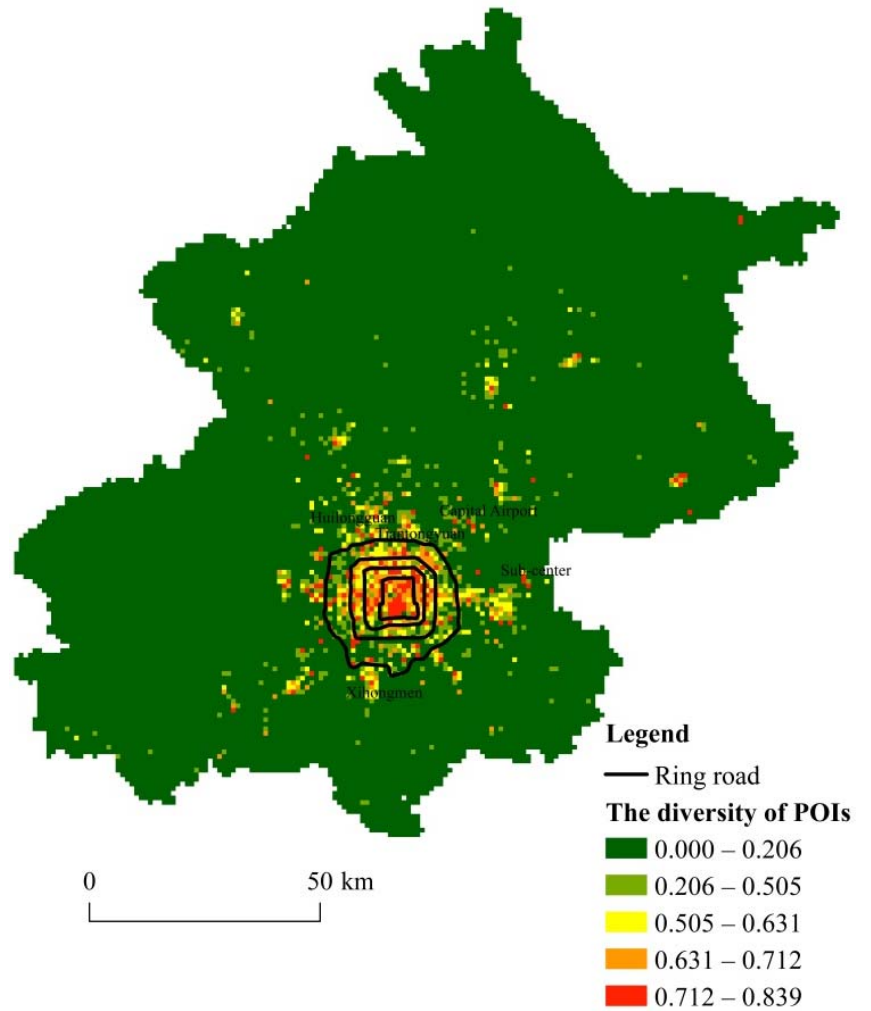

(a)

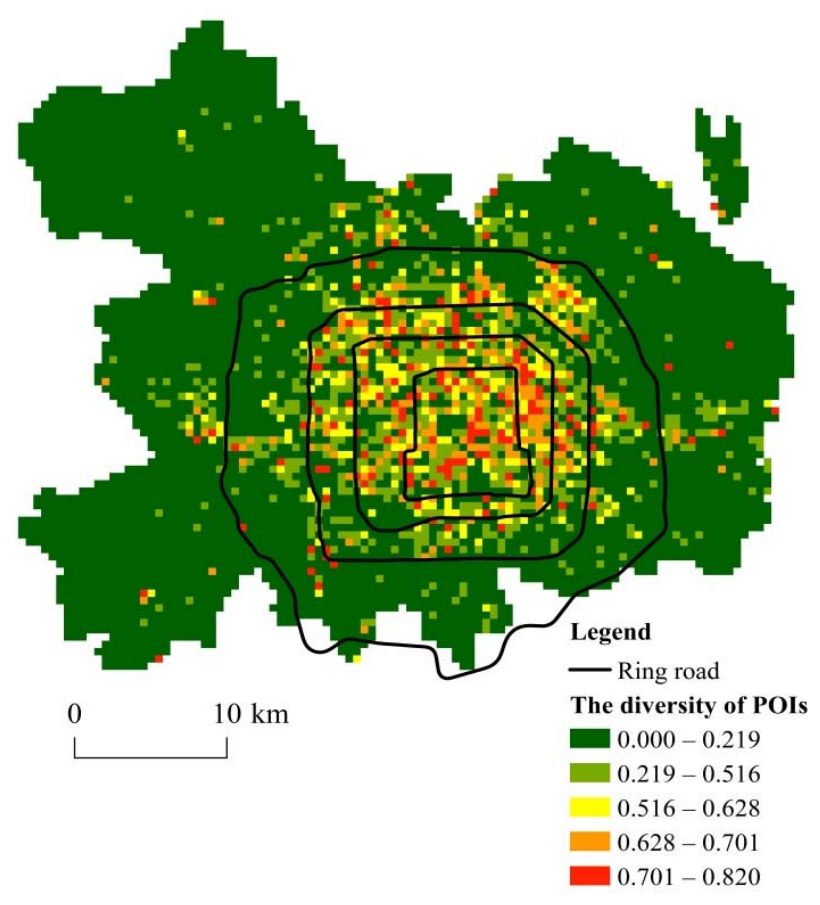

(b)

Figure 2. The distribution of the diversity of cultural and entertainment facilities (POIs) in Beijing. (a) City area; (b) Six urban districts.

\subsubsection{Spatial Distribution of Various Facilities}

The POIs of eight types of facilities were analyzed by grid superposition in the city area and six urban districts in Beijing. The results are as follows.

(1) The spatial distribution of various facilities in the city area varies

The eight types of facilities are generally concentrated in the central city, especially the core area, decreasing in number from the center to the periphery. The core area is the focus of the national political, cultural and international exchange center, a key area for the protection of historical and cultural cities and an important window area for displaying the image of the national capital. The number of leisure and fitness venues here exceeds half of the total facilities in the city area. In addition, the concentration of cafes is greatest in this area. The number of tea houses is equal to that of parks and amusement parks, but the concentration of tea houses is much higher than that of parks and amusement parks. The difference in the number of clubs and cafes between the urban and rural areas is the most significant, showing a strong polarization structure, while the difference in the number of parks and amusement parks and sports and fitness venues is relatively smaller, and the distribution is relatively even (Figure 3). 


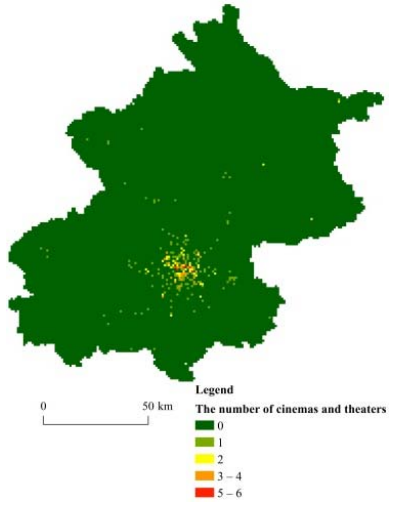

(a)

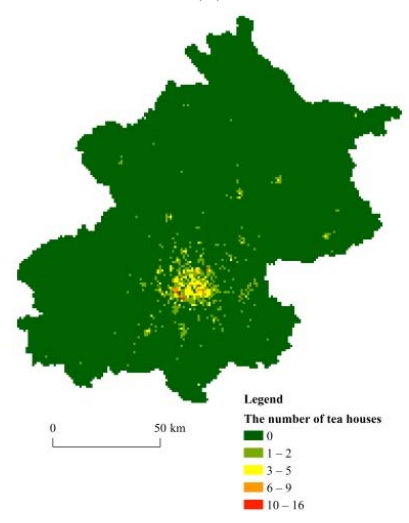

(e)

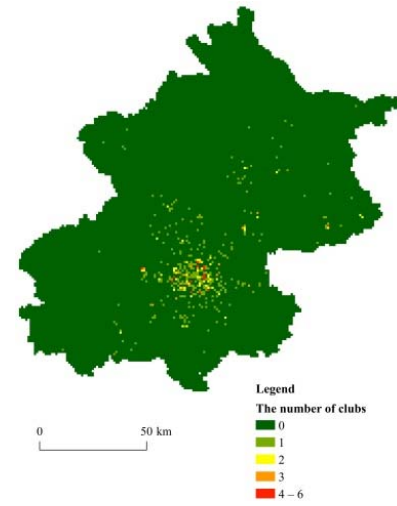

(b)

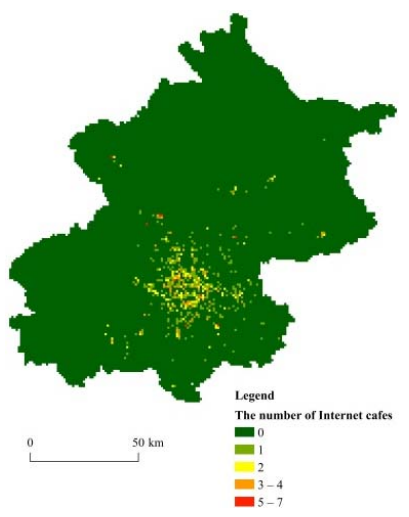

(f)

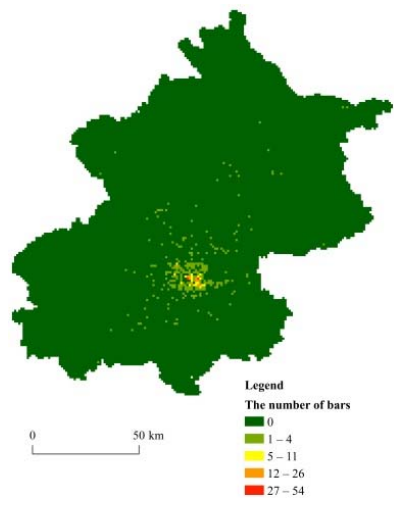

(c)

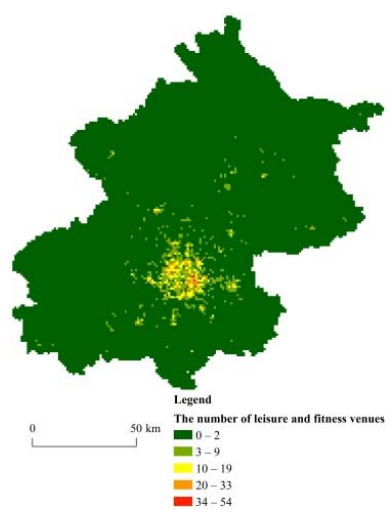

(g)

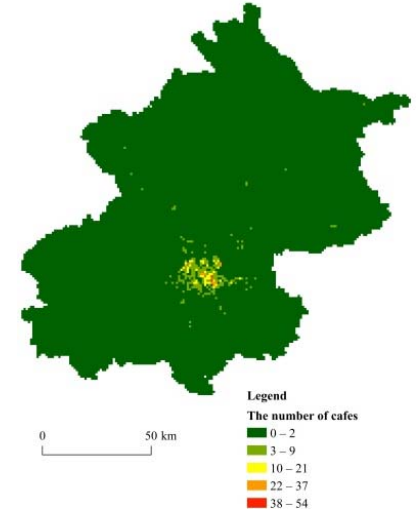

(d)

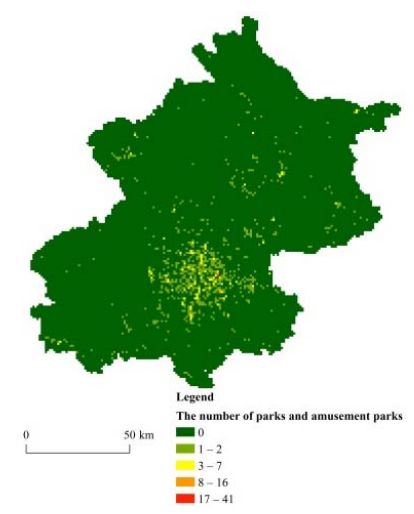

(h)

Figure 3. The distribution of single-type cultural and entertainment facilities in the city area in Beijing. (a) Cinemas and theatres; (b) Clubs; (c) Bars; (d) Cafes; (e) Tea houses; (f) Internet cafes; (g) Leisure and fitness venues; (h) Parks and amusement parks.

(2) Uneven distribution of various facilities in the six urban districts

The distribution of facilities highlights that different facilities have very different characteristics, both agglomerated and dispersed. Bars, cafes, cinemas and theaters and leisure and fitness venues had a significant tendency to agglomerate. For the bars and cafes, they tend to gather in the middle of the eastern part of the six urban districts. Cinemas and theaters have a significant agglomeration effect in the city center. Leisure and fitness venues tend to gather in the areas with high-end industries and provide leisure and fitness services for practitioners. The aggregation characteristics of tea houses, clubs, internet cafes and parks and amusement parks are relatively weak (Figure 4). 


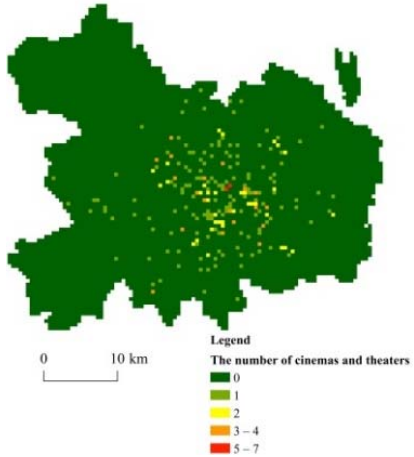

(a)

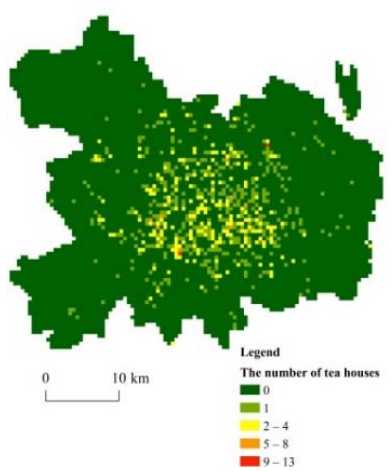

(e)

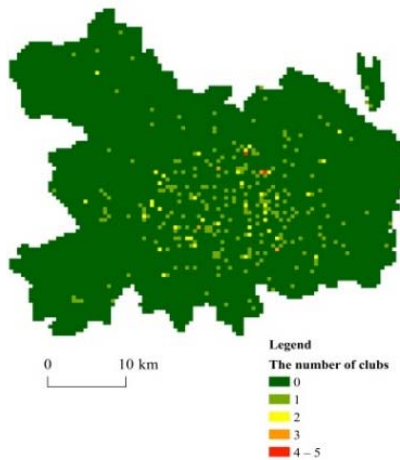

(b)

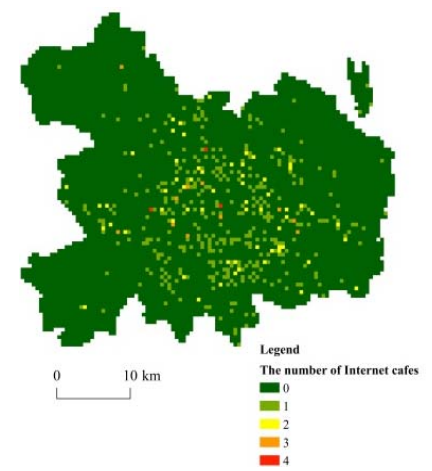

(f)

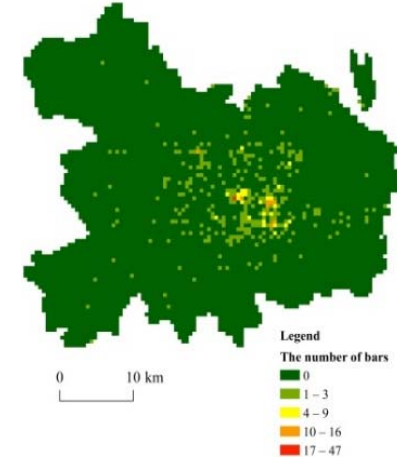

(c)

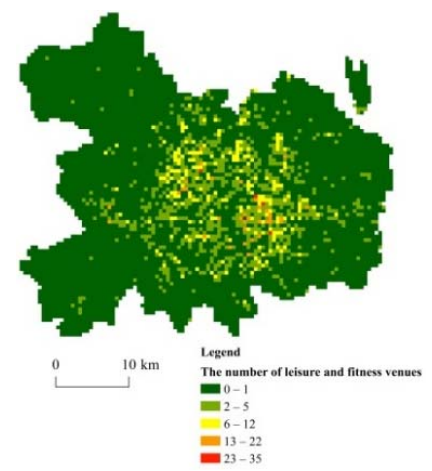

(g)

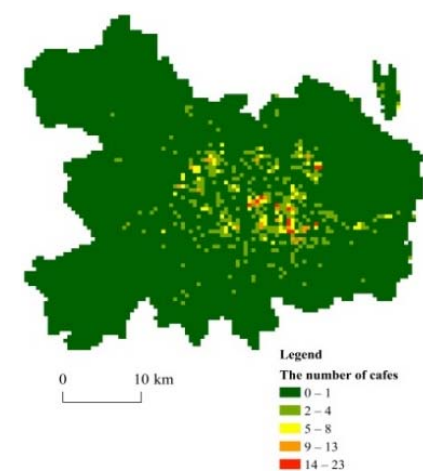

(d)

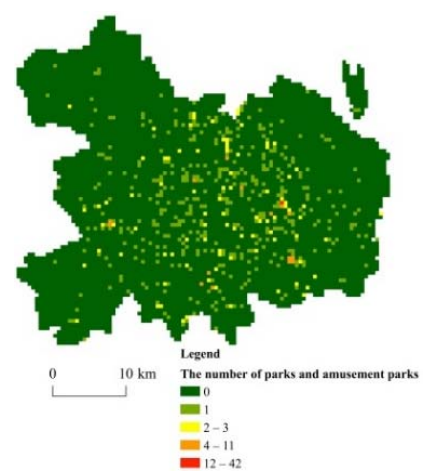

(h)

Figure 4. The distribution of single-type cultural and entertainment facilities in the six urban districts in Beijing. (a) Cinemas and Theatres; (b) Clubs; (c) Bars; (d) Cafes; (e) Tea houses; (f) Internet cafes; (g) Leisure and fitness venues; (h) Parks and amusement parks.

\subsubsection{Spatial Distribution of Overall Facilities}

First, based the statistics on the number of POIs in the grid, the spatial distribution of POIs is mapped (Figure 5). Cultural and entertainment facilities in Beijing are strongly concentrated in the central urban area. The number decreases from the city center, and in all directions outside the Fifth Ring Road, but it is linearly distributed along the main traffic lines. The gap between urban and rural areas is still large, and there is no distribution of very large numbers of facilities outside the six urban districts. The cultural and entertainment facilities have a huge urban-rural difference, the center-peripheral structure is significant and the number of facilities in the peripheral areas is too low. At the scale of the six urban districts, the areas with a higher density of cultural and entertainment facilities are between the East Second Ring Road and the East Fourth Ring Road, as well as the Northwest Fourth Ring Road. Among them, the number between the East Second Ring Road and the East Fourth Ring Road is extremely high. A core-peripheral structure appears in the areas within and outside the Fourth Ring Road.

Based on the kernel density method, the distribution hotspots of cultural and entertainment facilities in the city area and in the six urban districts in Beijing were detected. As can be seen from Figure 6a, the hotspots of cultural and entertainment facilities are mainly distributed in the central city, while in the suburbs, the hotspots are only in the area where the district government is located. Figure $6 \mathrm{~b}$ shows that facilities are mainly distributed within the Third Ring Road in the urban area, and there is the largest number of facilities in the CBD (Central Business District)-Sanlitun area between the East Second Ring Road and the Third Ring Road, and Shichahai and the Forbidden City also have hotspots. The overall hotspot pattern presents a spatial pattern centered on Shichahai, Forbidden City and CBD-Sanlitun, radiating to their northeast and northwest directions, respectively. 


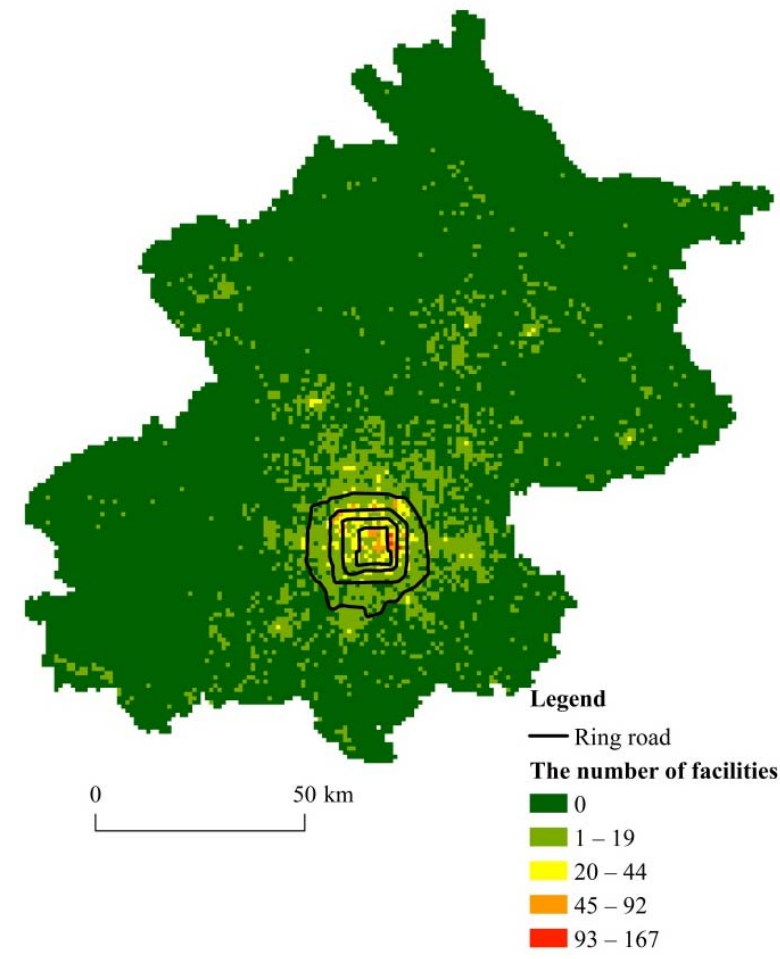

(a)

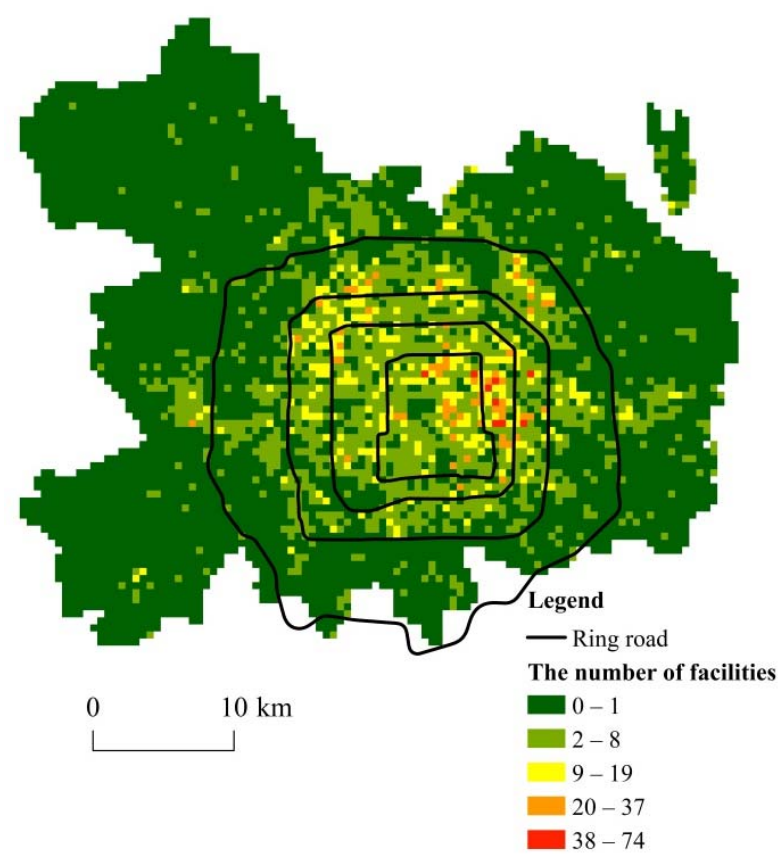

(b)

Figure 5. The grid spatial distribution of cultural and entertainment facilities in Beijing. (a) City area; (b) Six urban districts.

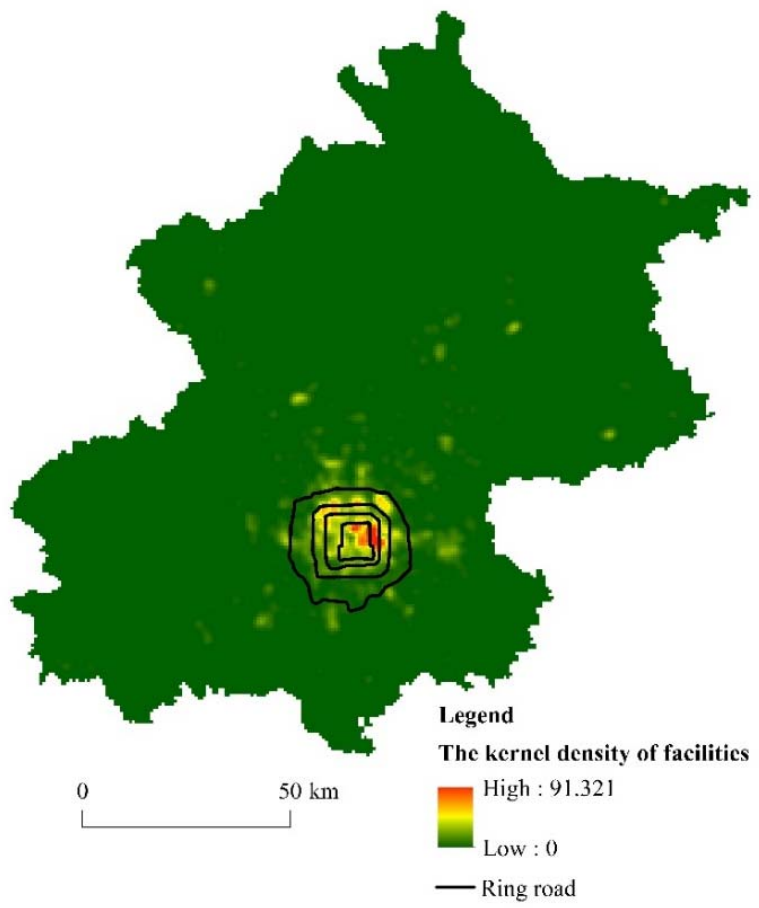

(a)

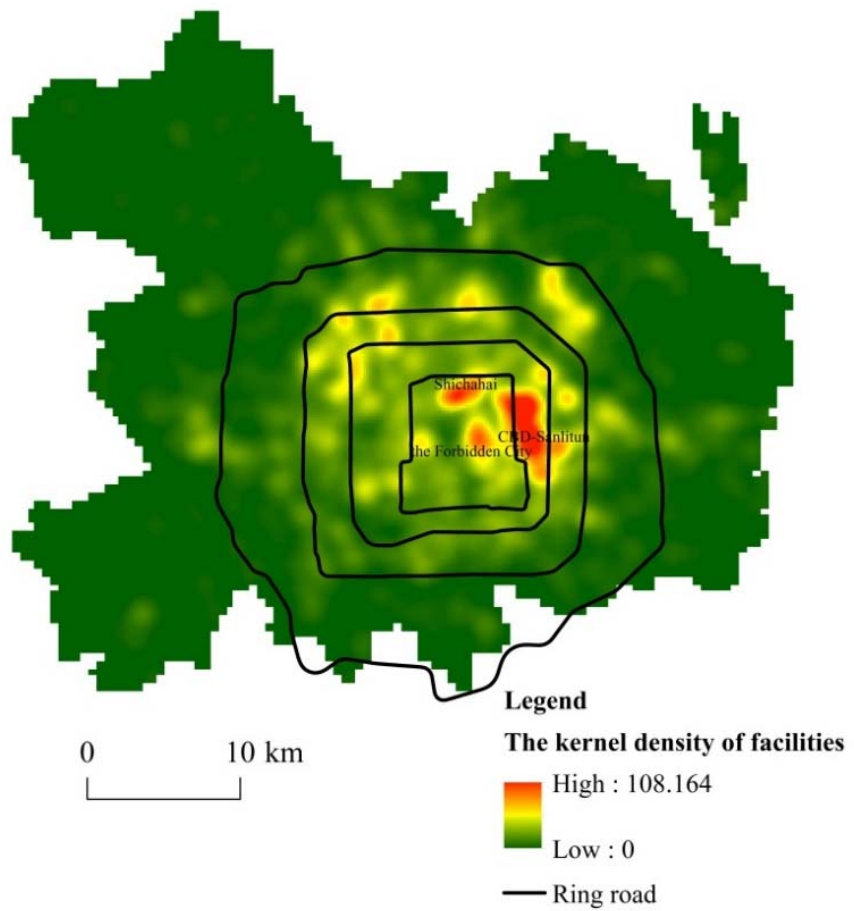

(b)

Figure 6. The kernel density map of cultural and entertainment facilities in Beijing. (a) City area; (b) Six urban districts. 


\subsubsection{Overall Clustering Characteristics of Facilities in the Six Urban Districts}

The nearest neighbor ratio of the various facilities is less than 1 , showing that the distributions of the facilities are all clustered. The probabilities ( $p$ values) are all 0 , indicating that the results all passed the significance test. The nearest neighbor ratio shows that the clustering characteristics of various facilities are generally in the strong and relatively strong clustering classes. All the facilities in the six urban districts generally belong to the strong clustering distribution characteristics. The nearest neighbor ratio is small for leisure and fitness venues and cafes, indicating a preference for clustering in areas with higher passenger through flow. Nearest neighbor ratios for internet cafes, cinemas and theaters and clubs are large, indicating wide scattering: Once one facility occupies a market, other facilities are unlikely to become established in the same market (Table 5).

Table 5. The summary of outcome of the nearest neighbor index method.

\begin{tabular}{|c|c|c|c|c|c|c|}
\hline Facility Type & $\begin{array}{l}\text { Facility } \\
\text { Number } \\
\text { (/Pc) }\end{array}$ & $\begin{array}{c}\text { Facility } \\
\text { Proportional (/\%) }\end{array}$ & $\begin{array}{c}\text { Average Nearest } \\
\text { Neighbor } \\
\text { Distance }(/ \mathrm{m})\end{array}$ & $\begin{array}{l}\text { Nearest } \\
\text { Neighbor } \\
\text { Ratio }\end{array}$ & $p$ Value & $\begin{array}{c}\text { Clustering } \\
\text { Characteristics }\end{array}$ \\
\hline $\begin{array}{l}\text { Six urban districts } \\
\text { summary }\end{array}$ & 10,890 & 100 & 80.3739 & 0.399279 & 0.0000 & Strong \\
\hline Cinemas and theaters & 296 & 2.72 & 625.0488 & 0.653577 & 0.0000 & Relatively strong \\
\hline Clubs & 338 & 3.10 & 706.1820 & 0.652541 & 0.0000 & Relatively strong \\
\hline Bars & 688 & 6.32 & 301.3833 & 0.457060 & 0.0000 & Strong \\
\hline Cafes & 2150 & 19.74 & 169.2556 & 0.417636 & 0.0000 & Strong \\
\hline Tea houses & 972 & 8.93 & 320.8711 & 0.540823 & 0.0000 & Relatively strong \\
\hline Internet cafes & 517 & 4.75 & 572.7397 & 0.683157 & 0.0000 & Relatively strong \\
\hline $\begin{array}{l}\text { Leisure and fitness } \\
\text { venues }\end{array}$ & 5224 & 47.97 & 118.0971 & 0.418664 & 0.0000 & Strong \\
\hline $\begin{array}{l}\text { Parks and } \\
\text { amusement parks }\end{array}$ & 705 & 6.47 & 466.1604 & 0.630203 & 0.0000 & Relatively strong \\
\hline
\end{tabular}

\subsubsection{Clustering Characteristics of Facilities in the Six Urban Districts at Different Scales}

Using multi-distance spatial cluster analysis, the clustering degree of cultural and entertainment facilities at the scales of different spatial distances is explored. According to the maximum value of the $\mathrm{L}(\mathrm{r})$ function, on average, the facilities in the six urban districts are gathered most prominently at around $\mathrm{r}=10 \mathrm{~km}$. The gathering of the bars is most prominent around $\mathrm{r}=7.22 \mathrm{~km}$, and they tend to gather in a very small spatial scale. With respect to the maximum value of the $\mathrm{L}(\mathrm{r})$ function, the bars rank first among all the facilities $(\max \mathrm{L}(\mathrm{r})=7.07)$, indicating that bars have the strongest clustering characteristics. The maximum value of the $\mathrm{L}(\mathrm{r})$ function for parks and amusement parks is 2.54 , which is the smallest among the eight facilities, indicating that the degree of clustering is the weakest (Figure 7). 


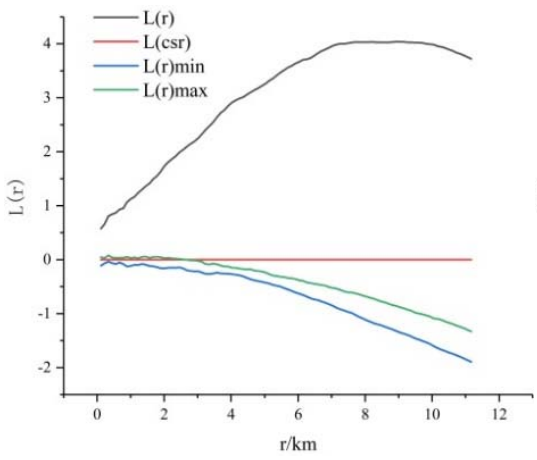

(a)

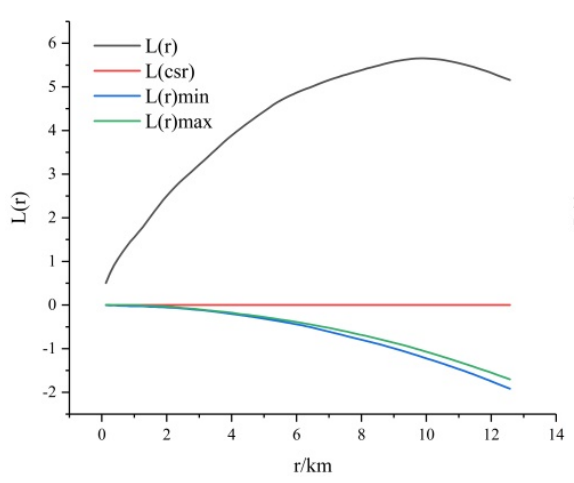

(d)

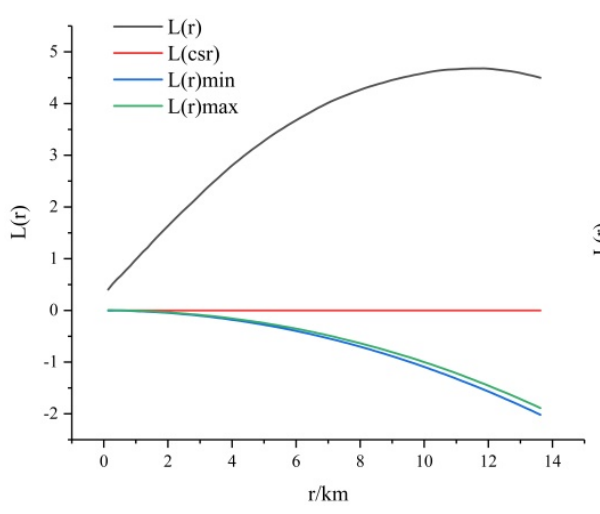

(g)

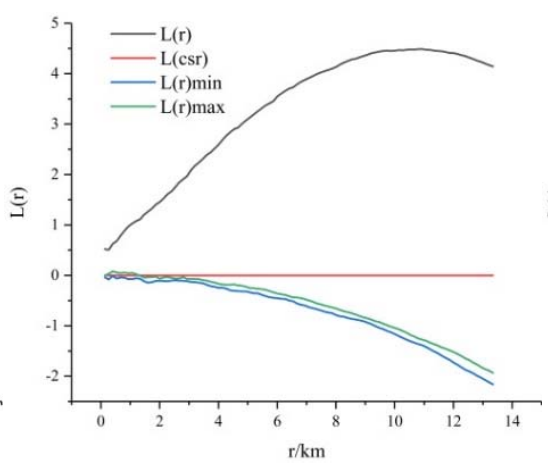

(b)

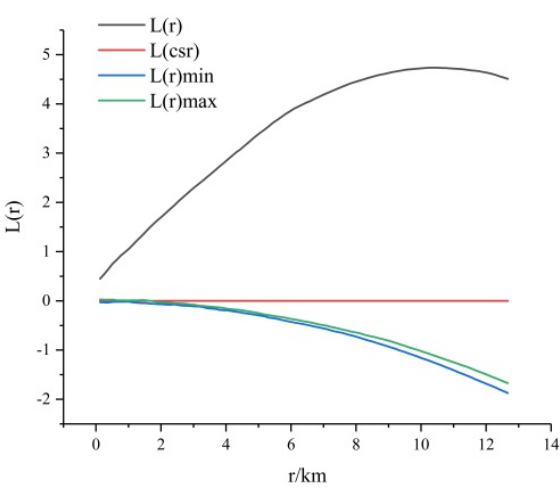

(e)

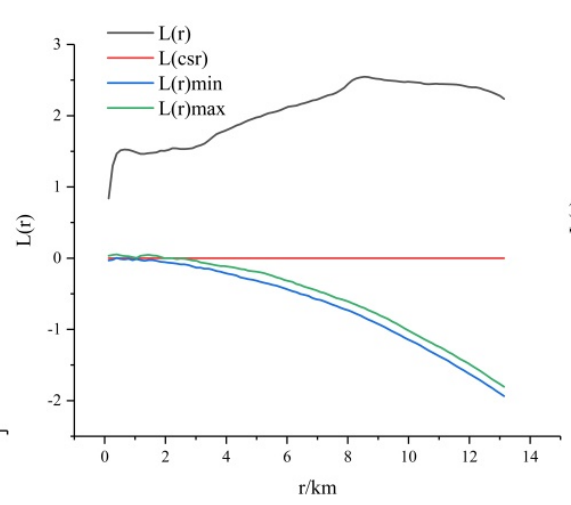

(h)

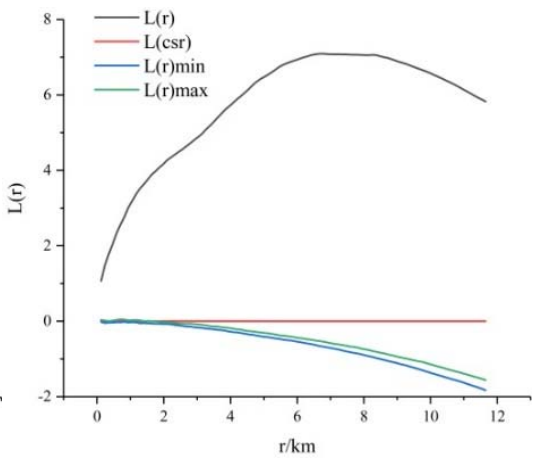

(c)

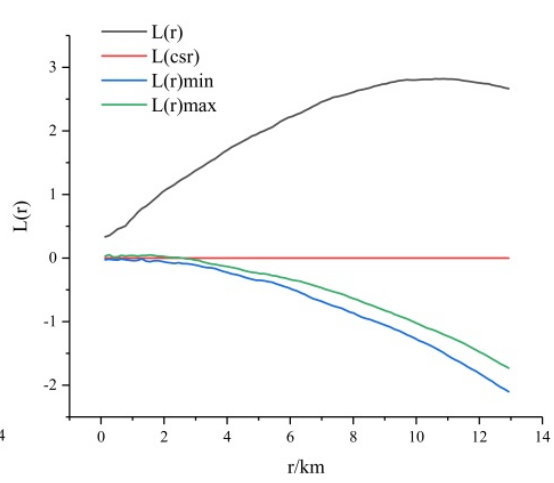

(f)

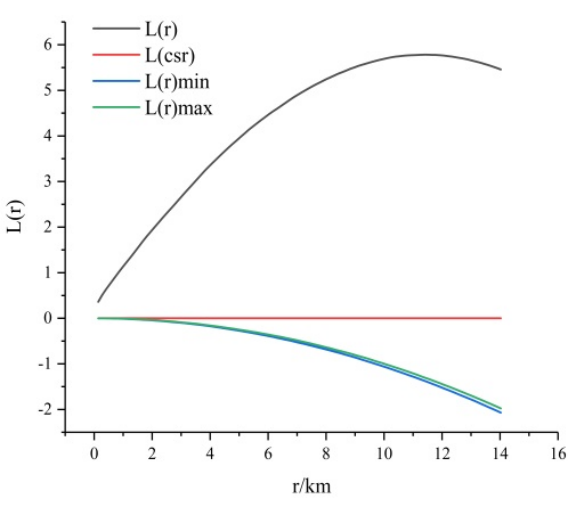

(i)

Figure 7. The clustering characteristics of various facilities at different scales in the six urban districts in Beijing. (a) Cinemas and theatres; (b) Clubs; (c) Bars; (d) Cafes; (e) Tea houses; (f) Internet cafes; (g) Leisure and fitness venues; (h) Parks and amusement parks; (i) All facilities.

\subsubsection{Hierarchical Clustering of Facilities in the Six Urban Districts}

After repeated tests, the clustering effect is the best when each hot spot of each cluster level contains at least 15 facilities. Figure 8 reveals that the distribution of hot spots is strongly heterogeneous, with greater numbers and more clusters on the east side. Secondary hot spots areas include Wudaokou, Zhongguancun, the North side of Zizhuyuan Park, Olympic Park, Shichahai, Wangjing, Sanlitun, CBD and Shuanging; these are areas with clustered facilities. Hotspots are also distributed along the East Second Ring Road. The areas between the East Second Ring Road and the East Third Ring Road have become centers for the provision of facilities and coincide with most of the crowded areas (such as 
Sanlitun, Dongdan, Shuangjing and CBD). These hotspot areas can be further divided into different types. The first category contains universities and enterprises with centralized orientations (such as Wudaokou); these have very high traffic, and college students and enterprise employees are major consumption objects. The second category is commercialcenter-oriented (such as Olympic Park and Shichahai). With many famous scenic spots and under the clustering effect of the business circle, a unique and complex space is formed that combines cultural tourism and shopping. The third category comprises centralizedoriented office spaces (such as the CBD), which are concentrated office and communication spaces for financial and business exchanges, business negotiations, office buildings, etc. The fourth category contains transportation hubs, train stations (such as Beijingxi Railway Station), bus stations, etc., which concentrate the flow of people and encourage neighboring commercial facilities. On the whole, six urban districts have developed different clustering characteristics of their cultural and entertainment facilities. The pattern of one core and multiple secondary cores have been formed. The first-level hot spots are mainly distributed in the eastern half of the city, and it covers Dongdan, Sanlitun, CBD, Shuangjing and other areas from the East Second Ring Road to the East Third Ring Road; the second-level hot spots tend to be distributed along the ring line; and the third level hot spots are scattered within the Fourth Ring Road.

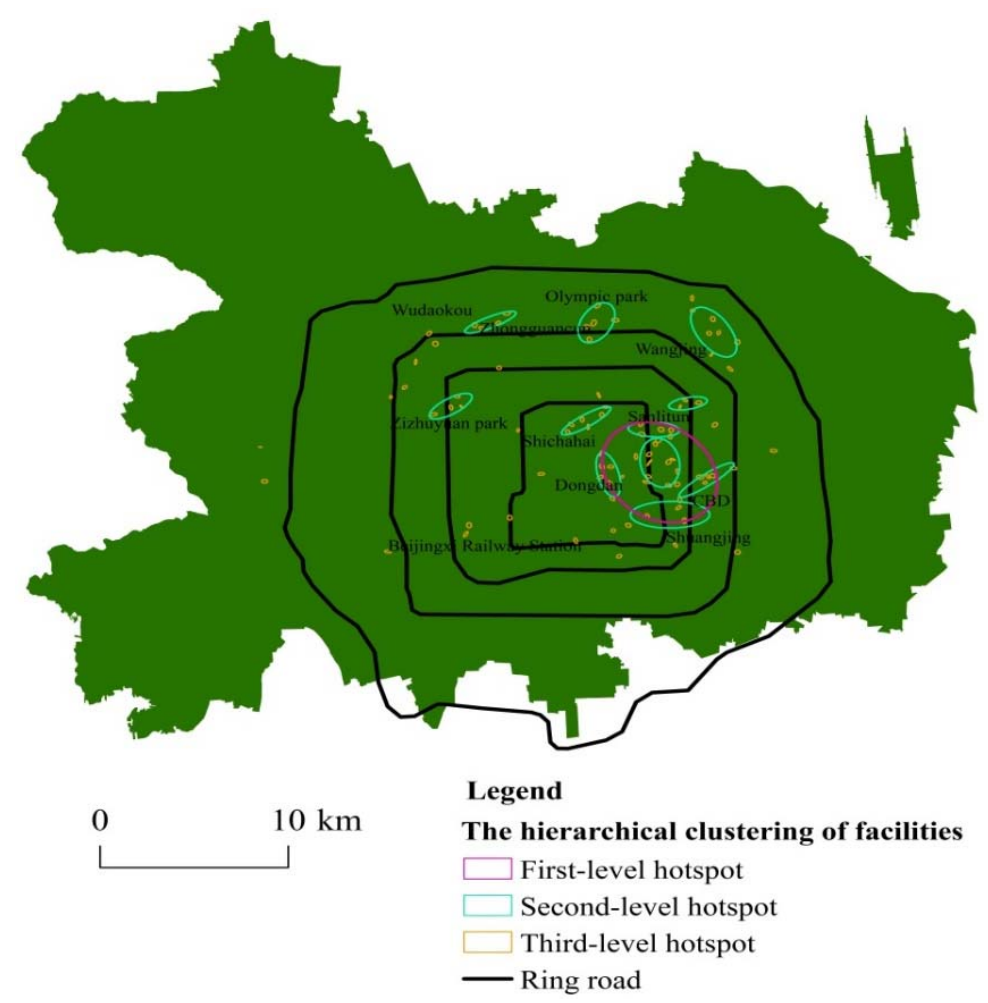

Figure 8. The outcome of hierarchical clustering of cultural and entertainment facilities in the six urban districts in Beijing.

\subsection{Factors Influencing the Distribution of Facilities in the Six Urban Districts}

After the aforementioned multi-collinearity test, our independent variables have become eight. After running OLS regression and spatial lag regression in GeoDa 1.6.7 (developed by Luc Anselin), we obtain the following results (Table 6). Here, the $\mathrm{R}^{2}$ for the spatial lag regression equation is 0.72 , demonstrating a good level of fit. This value improved when compared to the $\mathrm{R}^{2}$ of 0.71 from the OLS regression. At the same time, the value of the SC (Schwarz Criteria) is less than 0 and has declined, thus demonstrating that the regression model is more convincing. Table 6 shows that $p$-values of housing rent, the distance to the nearest scenic spot, the financial insurance institution density, the security company density and the building density in streets and towns are all less than 
0.05; therefore, they all pass the significance test at the $95 \%$ confidence interval. From the regression coefficients, we find that the road network density, housing rent, financial insurance institution density and building density are positively correlated with the density of facilities. Comparing the various coefficients, we can see that the degree of influence decreases in the following order: financial insurance institutions density $>$ building density $>$ security company density $>$ housing rent $>$ distance to nearest scenic spot. The distance to the nearest scenic spot and security company density are two negatively correlated factors.

Table 6. The regression outcome of spatial lag model.

\begin{tabular}{cccc}
\hline Variable & Regression Coefficient & Standard Error & Z Value \\
\hline POI_den & 0.164 & 0.095 & 1.720 \\
constant & 0.033 & 0.050 & 0.658 \\
luwang_den & 0.119 & 0.073 & 1.631 \\
zhugandao & -0.032 & 0.064 & -0.496 \\
housing rent & 0.276 & 0.072 & 3.845 \\
fengjingqu & -0.144 & 0.063 & -2.292 \\
jinrong_den & 0.410 & 0.124 & 3.314 \\
zhengquan_den & -0.341 & 0.118 & 0.000 \\
louyudasha_den & 0.393 & 0.098 & -2.886 \\
landprice & -0.064 & 0.106 & 0.001 \\
\end{tabular}

\section{Discussion}

At first, based on the results obtained above, we further discuss the spatial distribution characteristics of cultural and entertainment facilities and their influencing factors.

When it comes to the diversity of cultural and entertainment facilities, the traffic accessibility and the urban historical and cultural heritage are conducive to enhancing cultural and entertainment diversity. In addition, the reasons for the diversity of cultural and entertainment facilities may be that the effect of the policy that the proposal of Beijing's sub-center was released in 2016. The southern part's economic and industrial strength is relatively weak, which inhibits the diverse distribution of the cultural and entertainment industry in this place.

For the spatial distribution of various cultural and entertainment facilities, the leisure and fitness venues and parks and amusement parks are relatively even, because they are public welfare venues and are mostly planned and arranged by the government to meet the daily leisure needs of surrounding residents, and more consideration is given to the principle of balance. However, cafes, tea houses, etc., are profit-making establishments and are mainly distributed according to market demand behaviors. Most of them are concentrated in areas with dense populations, convenient transportation, developed commerce and active social and economic activities. In the six urban districts, for the bars and cafes, they tend to gather in the middle of the eastern part. The reason for this may be that a large number of foreigners lived near the Sanlitun embassy area in the early days, so bars and cafes developed here first. Another reason may be that after the reform and opening up, the business and financial formats of CBD have grown rapidly and have become a gathering place for foreigners' business exchanges. Cinemas and theaters have a significant clustering effect in the center. The reason is that most of the historical districts in Beijing are in the center. Traditional and historical performance projects (acrobatics, cross talk, etc.) promoted the early concentration and distribution of theaters in the city center. Cinemas are mostly distributed in prosperous areas, so they also present a concentrated distribution. The clustering characteristics of tea houses, clubs, internet cafes and parks and amusement parks are relatively weak. The reason for their even distribution is that the housing distribution in the six urban districts is relatively even, and such facilities usually serve the local citizens first.

The cultural and entertainment facilities have such a huge urban-rural difference and a center-peripheral structure. The reasons for this are as follows: first, Beijing's western and 
northern mountainous areas have a large area, and the southeast plain has more villages. The cultural and entertainment facilities are mostly rendered to the living configuration of urban residents, therefore, the peripheral area is not conducive to the distribution and development of related facilities; second, Beijing has improved its "pancake" urban expansion model and is undergoing a connotative and intensive development route. Therefore, Beijing's industrial development and the population density at this stage are still concentrated within the Fifth Ring Road. Due to the limited scale of industrial expansion in the suburbs, it is difficult to promote the development of new cities. Therefore, it is difficult for cultural and entertainment facilities to grow on a large scale in the peripheral areas of the city and only a small amount of distribution near the residence.

For the clustering characteristics of facilities in the six urban districts at different scales, compared with other facilities, bars tend to gather at the smallest spatial scale, indicating that bars tend to compete for a large number of human traffic within a small area. In addition, bars have the strongest clustering characteristics, and the reason for this may be that with the historical background of Beijing, Sanlitun and the CBD area were the places where foreigners concentrated in the early days. Thus, bars were the first to gather here and still maintained the most significant clustering until now. The degree of clustering of parks and amusement parks is the weakest. This is related to the green space service provided by the parks for the life of urban residents. It also shows that the construction of municipal parks and amusement parks is not clustered, thus facilitating residents' life and improving infrastructure construction.

For the factors influencing the distribution of facilities, the greater density of the road network and higher housing rent are associated with a greater number of cultural and entertainment facilities. The facilities tend to follow the spatial layout of high-end residential areas. In places with a high density of financial insurance institutions, and many buildings and high-quality employment spaces have encouraged cultural and entertainment facilities, leading to a directional distribution of employment spaces. However, the distance to nearest scenic spot and the securities company density are two negatively correlated factors. The former shows that the distribution of cultural and entertainment facilities tends to be adjacent to the scenic spots; the latter indicates that cultural and entertainment facilities may only be deployed in association with security companies in some streets and towns. However, in most areas where the density of security companies is relatively high, cultural and entertainment facilities are more sparsely distributed, probably because security companies are not concentrated in business districts or industrial parks.

The second is to compare with other similar studies. Compared with Zhou, Zhang, Dai et al. [46], our research pays more attention to the analysis of the basic pattern of POI, but lacks further analysis of the pattern, such as the analysis of spatial autocorrelation characteristics. Their research results show that historical and cultural sites have singlecenter distribution characteristics, but our cultural and entertainment facilities have multicenter distributions. Compared with Cui, Wang, Wu et al. [47], we have more types of cultural and entertainment facilities, but the discussion on the distribution of the road network structure and facilities is not so detailed, and we did not conduct an in-depth investigation of the spatial structure of the road network. They found that karaoke bars are highly clustered at the distance range of $2.5-3.0 \mathrm{~km}$, while any type of POIs are highly clustered at the distance range of 7 to $10 \mathrm{~km}$. Compared with Yi, Yang, Liu et al. [48], our research only focuses on cultural and entertainment facilities themselves and lacks extensive research on urban functions and cultural developments that reflect their spatial distribution patterns. Compared with Jing, Liu, Cai et al. [49], our research found the circle distribution characteristics of cultural and entertainment facilities, that is, the number decreases from the city center to the outside, but for the facilities at different distance from the city center, the distribution characteristics are not discussed, and their research found that the law of gradient change in leisure facilities from the center to the periphery.

Thirdly, we will render some suggestions for the development of Beijing's cultural and entertainment facilities. Comparing Figures 2 and 5, we can find that the diversity 
and quantity distribution patterns are not completely consistent. For areas with high population densities such as Huilongguan-Tiantongyuan, although the facilities are more diverse, the number is relatively small. Therefore, in the layout and planning of the cultural and entertainment industry, the living needs of community residents should be considered. In areas with high residential population density, the number of cultural and entertainment facilities should be appropriately increased to meet the structure of the community's cultural life circle. Then, we found that according to the regression results of the spatial lag model, in the six urban districts, housing rent and the distribution of cultural and entertainment facilities have a significant positive correlation. Therefore, for residents living in the places of lower housing rents, they may not be able to enjoy enough cultural and entertainment service. The government should introduce inclusive cultural and entertainment facilities to meet the development needs of regional cultural and entertainment industries for these residents and to promote the fairness of urban public facilities supply. In addition, Beijing's mid- to long-term plan (2019-2035) for promoting the construction of a national cultural center puts forward, turn the South Fifth Ring Area into a functional area for national culture and international communication, and build a new gateway for international communication in the southern part of the city. According to our results, the South Fifth Ring District is a cold spot for cultural and entertainment facilities, whether it is on the scale of city area or the six urban districts. Therefore, one of the focuses of the layout and planning of cultural and entertainment facilities in Beijing should focus on the South Fifth Ring area in the future. According to the results of the regression, it is a feasible way to introduce mid-to-high-end industries to drive the growth of cultural and entertainment facilities and attract related investment, which will ultimately benefit the lives of regional residents and make this area become a new cultural landmark and a new gateway.

The data volume, coverage, accuracy, update frequency and other aspects of POI data from the domestic internet electronic map are considered to generally meet the needs of basic POI data for GIS applications in different industries. This paper uses the currently popular internet capture big data technology to collect Baidu map POI data and conducts a spatial analysis of urban cultural and entertainment facilities, thus adopting a different approach from the previous ways of collecting statistical data. However, the experimental data are from a single POI data source, and they are mostly studied from a spatial perspective, without the concept of time. Future research is expected to add the element of time to further study the temporal and spatial evolution processes and influencing factors of the formation, clustering and development of urban culture and entertainment facilities. What is worth mentioning is the classification of cultural and entertainment facilities. According to the Classification of Culture and Related Industries (2018) issued by the National Bureau of Statistics and the research of some scholars, we divided cultural and entertainment facilities into eight categories, but there are still some limitations: First, parks and amusement parks are grouped into one category. It is obvious that natural, cultural and amusement parks are not suitable for being classified into one category; in addition, unlike tea houses and cafes, bars and internet cafes may play a small role in the spread and exchange of culture, therefore, whether they should be classified as cultural and entertainment facilities is also a matter that is worth exploring. When setting factors that affect the distribution of cultural and entertainment facilities, our analysis for the road network is relatively superficial, and in-depth indicators such as accessibility and topological structure characteristics should be added in the future. In addition, big data have the characteristics of fine granularity, fine scale, large sample size and wide coverage. Meanwhile, traditional questionnaire data have shortcomings such as small sample size, challenging collection, poor timeliness and poor representativeness, amongst others. In the future, we can try to combine big data and small data and add human spatiotemporal behavior factors into the research on the factors affecting the distribution of cultural and entertainment facilities. This will further explore influences on the distribution of cultural 
and entertainment facilities, to a certain extent, to enrich and deepen the research on the spatial layout and influencing factors of cultural and entertainment facilities.

The contribution of this research is to analyze the spatial distribution characteristics of Beijing's overall cultural and entertainment facilities and different types of cultural and entertainment facilities, as well as the clustering characteristics and influencing factors of cultural and entertainment facilities in the six urban districts. Another contribution is the findings of the unbalanced characteristics of the spatial distribution of cultural and entertainment facilities, the scale effect of the spatial agglomeration of different types of facilities, and the socio-economic and built environment factors that have a significant impact on the distribution of cultural and entertainment facilities. The results can provide a reference for more reasonable layout planning of cultural and entertainment facilities, stimulating regional cultural vitality, ensuring the efficient development and utilization of Beijing's local cultural resources, optimizing the quality of urban cultural space and coordinating the spatial distribution of the cultural and entertainment industry with other industries.

\section{Conclusions}

To more objectively present the spatial distribution of urban cultural and entertainment facilities in Beijing, location-based interest data (POI) are undoubtedly an important choice. The Simpson Index was used to detect the diversity of the spatial distribution of cultural and entertainment facilities. The grid method and kernel density method were used to analyze the spatial distribution of cultural and entertainment facilities. The nearest neighbor index, the $\mathrm{K}$ function and the nearest neighbor hierarchical cluster analysis were used to analyze the clustering characteristics of the facilities in the urban six districts. Finally, a spatial regression model was constructed to analyze the influence of the social, economic and built environment factors on the spatial distribution of the facilities in six urban districts. The conclusions are as follows.

Regarding the spatial distribution of the diversity of cultural and entertainment facilities, the diversity within the Fourth Ring Road is relatively high.

The overall cultural and entertainment facilities have a significant center-peripheral structure. The hotspots of cultural and entertainment facilities are mainly distributed in the center of Beijing, while in the suburbs, the hotspots are only in the area where the district government is located.

The facilities in the six urban districts are generally clustered, but the clustering degree varies between different types of facilities. The most significant range of facility clustering characteristics is found within a radius of $10 \mathrm{~km}$. Bars tend to gather in a very small spatial scale compared with other type facilities.

The cultural and entertainment facilities in the six urban districts can be divided into three levels of agglomeration hotspots. These agglomeration hotspots are closely related to environmental factors such as commerce, employment, traffic and universities.

The factors that characterize the social and economic vitality and the built environment have an important impact on the spatial distribution of cultural and entertainment facilities in Beijing. Financial insurance institution density, building density, security company density, housing rent and the distance to the nearest scenic spot are the main factors affecting the distribution of cultural and entertainment facilities in Beijing.

Author Contributions: Conceptualization, D.H. and S.A.; data curation, Z.C. and T.Y.; formal analysis, D.H., J.Z. and L.L.; funding acquisition, D.H.; investigation, D.H. and J.Z.; methodology, D.H., J.Z. and L.L.; project administration, D.H. and S.A.; resources, J.Z.; software, Z.C.; supervision, D.H. and S.A.; validation, Z.C. and T.Y.; visualization, D.H. and Z.C.; writing-original draft, D.H.; writing-review and editing, D.H., S.A., J.Z. and L.L. All authors have read and agreed to the published version of the manuscript. 
Funding: This research was jointly supported by the Beijing Social Science Fund (No. 19JDGLA006, 14CSC015), the Premium Funding Project for Academic Human Resources Development in Beijing Union University (No. BPHR2017CZ01), the Academic Research Projects of Beijing Union University (No. ZK40202001), Major Scientific Research Incubation Project of Beijing Union University (No. RB202101).

Institutional Review Board Statement: Not applicable.

Informed Consent Statement: Not applicable.

Data Availability Statement: The data presented in this study are available on request from the first author.

Acknowledgments: The authors would like to thank the anonymous reviewers and the editors for their insightful comments and suggestions.

Conflicts of Interest: The authors declare no conflict of interest.

\section{References}

1. Zhang, B.; Wang, X.Z. The study of spatial structures of the urban commercial entertainment places. Sci. Geogr. Sin. 2007, 27, 853-858.

2. McCarthy, J. Entertainment-led regeneration: The case of detroit. Cities 2002, 19, 105-111. [CrossRef]

3. Ahmed, F.; Zuk, A.; Tsuji, L. The Impact of Land-Based Physical Activity Interventions on Self-Reported Health and Well-Being of Indigenous Adults: A Systematic Review. Int. J. Environ. Res. Public Health 2021, 18, 7099. [CrossRef] [PubMed]

4. Christiansen, E.M. Book review of Entertainment Industry Economics: A guide for financial analysis, third edition. J. Gambl. Stud. 1995, 11, 381-385. [CrossRef]

5. Jean, B. The Consumer Society: Myths and Structures; Sage: London, UK, 1998

6. Kooijman, D. A third revolution in retail? The Dutch approach to leisure and urban entertainment. J. Retail. Leis. Prop. 2002, 2, 214-229. [CrossRef]

7. Teschke, K.; Chow, Y.; Netten, C.; Varughese, S.; Kennedy, S.M.; Brauer, M. Exposures to Atmospheric Effects in the Entertainment Industry. J. Occup. Environ. Hyg. 2005, 2, 277-284. [CrossRef]

8. Jiang, S.J.; Zhang, H.P.; Wang, H.R.; Zhou, L.; Tang, G.A. Using Restaurant POI Data to Explore Regional Structure of Food Culture Based on Cuisine Preference. ISPRS Int. J. Geo-Inf. 2021, 10, 38. [CrossRef]

9. Gratz, R.B.; Mintz, N. Cities Back from the Edge: New Life for Downtown; Preservation Press: New York, NY, USA, 1996; pp. 265-268.

10. Kanbur, R.; Zhuang, J. Urbanization and Inequality in Asia. Asian Dev. Rev. 2013, 30, 131-147. [CrossRef]

11. Sartorius, K.; Sartorius, B. Service delivery inequality in South African municipal areas: A new way to account for interjurisdictional differences. Urban Stud. 2016, 53, 3336-3355. [CrossRef]

12. He, S.; Qian, J. From an emerging market to a multifaceted urban society: Urban China studies. Urban Stud. 2016, 54, 827-846. [CrossRef]

13. Sun, X.; Wang, W.; Sun, T.; Wang, Y.P. Understanding the Living Conditions of Chinese Urban Neighborhoods through Social Infrastructure Configurations: The Case Study of Tianjin. Sustainability 2018, 10, 3243. [CrossRef]

14. Hao, F.L.; Wang, S.J. Spatial distribution characteristics of entertainment venues in Changchun urban area based on the public praise from internet. Hum. Geogr. 2016, 31, 66-72, 108.

15. He, D.; Jin, F.J.; Dai, T.Q.; Sun, Y.; Zhou, Z.Y. Spatial patterns and characteristics for service level of urban public cultural facilities in central Beijing. Prog. Geogr. 2017, 36, 1128-1139.

16. Zhao, S.T.; Zhang, W.X. Characteristics of spatial-temporal evolution and accessibility of public cultural facilities in Beijing. Urban Dev. Stud. 2020, 27, 7-12.

17. Zhai, X.J.; Sun, X.H.; Sun, Z.Y. Research on the quantity and distribution characteristics of public cultural facilities in central area of Zibo city based on POI data. J. Shandong Norm. Univ. Nat. Sci. 2017, 32, 73-79.

18. Ryder, A. The changing nature of adult entertainment districts: Between a rock and a hard place or going from strength to strength? Urban Stud. 2004, 41, 1659-1686. [CrossRef]

19. Zhou, S.Y.; Jiang, M.M.; Wu, L.P. Characteristics of spatial distribution of cultural industry in Beijing urban area. J. Beijing Norm. Univ. Soc. Sci. 2006, 6, 127-133.

20. Xue, D.Q.; Liu, H.; Ma, B.B. Characteristics of spatial distribution of cultural industries in urban area of Xi'an city, China. Sci. Geogr. Sin. 2011, 31, 775-780.

21. Xue, D.Q.; Huang, J.; Ma, B.B.; Kang, Y.L. Spatial distribution characteristics and hot zone patterns of entertainment industry in Xi'an. Acta Geogr. Sin. 2014, 69, 541-552.

22. Zhang, Y.K.; Li, S.Y.; Tan, L.F.; Zhou, J.Y. Distribution and Integration of Military Settlements' Cultural Heritage in the Large Pass City of the Great Wall in the Ming Dynasty: A Case Study of Juyong Pass Defense Area. Sustainability 2021, 13, 7166. [CrossRef]

23. Huang, L.; Zhou, J. Spatial distribution and influencing factors of city cafes in Shanghai. Mod. Urban Res. 2019, 3, 42-49. 
24. Jia, X.T.; Lei, J.; Wu, R.W.; Wang, B.L. Urban recreation space pattern based on POI data: A case of Urumqi City. Arid. Land Geogr. 2019, 42, 943-952.

25. Yang, X.J.; Zhu, K.K.; Chen, P.Y.; Guo, W.H. Spatial distribution characteristics and temporal-spatial evolution of urban cinemaA case study of Xi'an. Econ. Geogr. 2018, 38, 85-93.

26. Yu, L.; Yu, T.; Wu, Y.X.; Wu, G.D. Rethinking the Identification of Urban Centers from the Perspective of Function Distribution: A Framework Based on Point-of-Interest Data. Sustainability 2021, 12, 1543. [CrossRef]

27. Zhao, H.B.; Yu, D.F.; Miao, C.H.; Li, G.H.; Feng, Y.B.; Bie, Q.L. The location distribution characteristics and influencing factors of cultural facilities in Zhengzhou based on POI data. Sci. Geogr. Sin. 2018, 38, 1525-1534.

28. Kim, K.; Ghorbanzadeh, M.; Horner, M.W.; Ozguven, E.E. Identifying areas of potential critical healthcare shortages: A case study of spatial accessibility to ICU beds during the COVID-19 pandemic in Florida. Transp. Policy 2021, 110, 478-486. [CrossRef]

29. Kim, M.H.; Clarke, P.J.; Dunkle, R.E. Urban Neighborhood Characteristics and the Spatial Distribution of Home and CommunityBased Service Organizations in Michigan Metropolitan Statistical Areas. Res. Aging 2021, 01640275211005079. [CrossRef]

30. Pérez-Acebo, H.; Romo-Martín, A.; Findley, D.J. Spatial distribution and the facility evaluation of the service and rest areas in the toll motorway network of the European Union. Appl. Spat. Anal. Policy 2021, 14, 1-25. [CrossRef]

31. Gutiérrez, M.F.; Noguez, A.B.; Flamenco-Sandoval, A.; Serrano, A.M.; Flores-Torres, A.; Ramírez, A.K.G.; Alcántara, C. Availability and accessibility of urban green spaces: The case of the urban zone of Queretaro Metropolitan Area, Mexico. J. Maps 2021, 1-5. [CrossRef]

32. Bulletin of the Seventh National Census (No. 3). Available online: http://www.stats.gov.cn/tjsj/zxfb/202105/t20210510_181717 9.html (accessed on 15 October 2021).

33. Ma, S.Q.; Xue, Z.W.; Yang, L.L.; Kang, J.P.; Ma, Y.Y.; Han, L. Comparison of species diversity under heterogeneous habitats, determination and evaluation of diversity indices of desert riparian forest community in Tarim basin. Bull. Bot. Res. 2017, 37, 961-969.

34. Yan, Z.X.; Ji, M.H.; Song, T.X. Influential analysis of road networks on urban consumption vitality based on POI density and diversity: A case study of Shanghai. J. Suzhou Univ. Sci. Technol. Nat. Sci. 2017, 34, 73-80.

35. Zuo, Y.F.; Chen, H.; Pan, J.C.; Si, Y.Q.; Law, R.; Zhang, M. Spatial Distribution Pattern and Influencing Factors of Sports Tourism Resources in China. ISPRS Int. J. Geo-Inf. 2021, 10, 428. [CrossRef]

36. Lai, C.Q.; Wu, X.B. A study on spatial distribution characteristics of megacity hotels based on GIS method: A data analysis based on POI data of Guangzhou hotels. Mod. Urban Res. 2019, 8, 66-74.

37. Lu, C.; Pang, M.; Zhang, Y.; Li, H.; Lu, C.; Tang, X.; Cheng, W. Mapping Urban Spatial Structure Based on POI (Point of Interest) Data: A Case Study of the Central City of Lanzhou, China. ISPRS Int. J. Geo-Inf. 2020, 9, 92. [CrossRef]

38. Zhang, P.; Li, H.; Wang, J.; Hong, J. Analysis of Spatial Wharf Pattern of the Yangtze River Delta Urban Agglomeration, China. ISPRS Int. J. Geo-Inf. 2019, 8, 541. [CrossRef]

39. Bielecka, E.; Pokonieczny, K.; Borkowska, S. GIScience Theory Based Assessment of Spatial Disparity of Geodetic Control Points Location. ISPRS Int. J. Geo-Inf. 2020, 9, 148. [CrossRef]

40. Hassan, M.M.; Juhász, L.; Southworth, J. Mapping Time-Space Brickfield Development Dynamics in Peri-Urban Area of Dhaka, Bangladesh. ISPRS Int. J. Geo-Inf. 2019, 8, 447. [CrossRef]

41. Huang, X.J.; Huang, X. Regional differentiation of the coupling between urban physical environment and social space in Changchun. Econ. Geogr. 2012, 32, 21-26, 45.

42. Gao, C.; Feng, Y.; Tong, X.; Lei, Z.; Chen, S.; Zhai, S. Modeling urban growth using spatially heterogeneous cellular automata models: Comparison of spatial lag, spatial error and GWR. Comput. Environ. Urban Syst. 2020, 81, 101459. [CrossRef]

43. Chowdhury, T.; Scott, D.M. An analysis of the built environment and auto travel in Halifax, Canada. Transp. Policy 2020, 94, 23-33. [CrossRef]

44. Su, S.L.; Li, L.; Weng, M. Spatial Data Analysis; Science Press: Beijing, China, 2019.

45. Weng, M.; Li, L.; Su, S.L. Spatial Data Analysis Case-Based Experimental Tutorial; Science Press: Beijing, China, 2019.

46. Zhou, X.; Zhang, X.; Dai, Z.; Hermaputi, R.; Hua, C.; Li, Y. Spatial Layout and Coupling of Urban Cultural Relics: Analyzing Historical Sites and Commercial Facilities in District III of Shaoxing. Sustainability 2021, 13, 6877. [CrossRef]

47. Cui, C.; Wang, J.; Wu, Z.; Ni, J.; Qian, T. The Socio-Spatial Distribution of Leisure Venues: A Case Study of Karaoke Bars in Nanjing, China. ISPRS Int. J. Geo-Inf. 2016, 5, 150. [CrossRef]

48. Yi, D.; Yang, J.; Liu, J.; Liu, Y.; Zhang, J. Quantitative Identification of Urban Functions with Fishers' Exact Test and POI Data Applied in Classifying Urban Districts: A Case Study within the Sixth Ring Road in Beijing. ISPRS Int. J. Geo-Inf. 2019, 8, 555. [CrossRef]

49. Jing, Y.; Liu, Y.; Cai, E.; Liu, Y.; Zhang, Y. Quantifying the spatiality of urban leisure venues in Wuhan, Central China-GIS-based spatial pattern metrics. Sustain. Cities Soc. 2018, 40, 638-647. [CrossRef] 